Check for updates

Cite this: Mater. Adv., 2021 2, 582

Received 29th September 2020, Accepted 9th December 2020

DOI: $10.1039 / \mathrm{d} 0 \mathrm{ma} 00744 \mathrm{~g}$

rsc.li/materials-advances

\section{Zero-to-one (or more) nanoarchitectonics: how to produce functional materials from zero-dimensional single-element unit, fullerene}

\begin{abstract}
Katsuhiko Ariga (D) *ab and Lok Kumar Shrestha (D) ${ }^{a}$
In this review article, the potentials of the nanoarchitectonic approach are demonstrated from the viewpoint of the high capability of structure formation from simple fullerene units. The formation of materials with huge morphological variety from simple unit components, fullerenes $\left(C_{60}\right.$ and $\left.C_{70}\right)$, only through conventional procedures is exemplified. Although fullerenes are zero-dimensional units made only from a single element component, carbon, nanoarchitectonic processes from fullerene molecules provide one-dimensional, two-dimensional and three-dimensional motifs, and a further extension to complicated morphologies and hierarchical structures. The novel applications of nanoarchitected fullerene materials are also described by showing their usages in micro-scale material recognition and fate regulation of living cells. It is said that true innovation relies on the idea to create one from zero. This review article demonstrates this true innovation capability of nanoarchitectonics in material advances.
\end{abstract}

\section{Introduction}

The synthesis and fabrication of functional materials are indispensable keys for solving problems in the current society,

\footnotetext{
${ }^{a}$ WPI Research Center for Materials Nanoarchitectonics (MANA), National Institute for Materials Science (NIMS), 1-1 Namiki, Tsukuba, Ibaraki 305-0044, Japan. E-mail: ARIGA.Katsuhiko@nims.go.jp

${ }^{b}$ Graduate School of Frontier Sciences, The University of Tokyo, 5-1-5 Kashiwanoha, Kashiwa, Chiba 277-8561, Japan
}

including energy production, ${ }^{1}$ energy management, ${ }^{2}$ sensing and detection, ${ }^{3}$ environmental remediations, ${ }^{4}$ and biomedical applications. ${ }^{5}$ Solutions for all these demands can be brought about by the properties and functions of materials fabricated for corresponding targets. The target materials have been produced by efforts in traditional scientific disciplines such as organic synthesis, ${ }^{6}$ polymer chemistry, ${ }^{7}$ supramolecular chemistry, ${ }^{8}$ and materials science. ${ }^{9}$

An innovative essence into these material processes has been added by the contribution of nanotechnology. Nanotechnological efforts have revealed the crucial importance of the regulation of

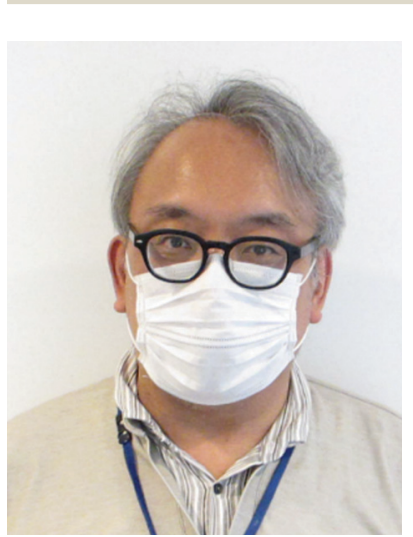

Katsuhiko Ariga
Katsuhiko Ariga received his PhD degree from the Tokyo Institute of Technology in 1990. He joined the National Institute for Materials Science (NIMS) in 2004 and is currently the leader of the Supermolecules Group and principal investigator of the World Premier International (WPI) Research Centre for Materials Nanoarchitectonics (MANA), NIMS. He is also appointed as a professor in The University of Tokyo.

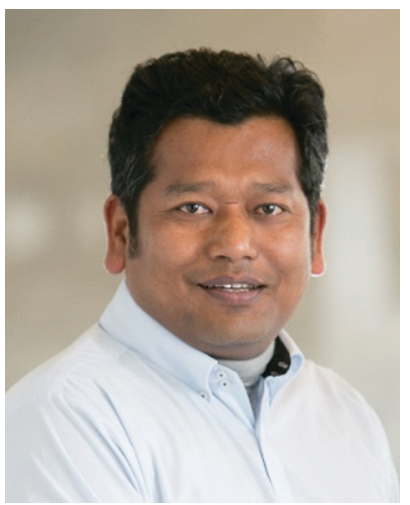

Lok Kumar Shrestha
Lok Kumar Shrestha is a Principal Researcher at the World Premier International Research Center for Materials Nanoarchitectonics (MANA) of the National Institute for Materials Science (NIMS). His current research interests include selfassembly of functional molecules fullerenes, functional nanomaterials design from zero-tohigher dimensions, mesoporous fullerene crystals and their conversion into mesoporous graphitic carbons, and production of the ultrahigh surface area nanoporous carbon materials from biomass for energy storage and sensing applications. 
nanostructures for material functions with high efficiency and high specificity. The understanding of nano-scale phenomena by high-resolution nano-level observation and precise fabrications even with atom/molecular-level manipulation opens high possibilities in the enhancement of material functions through the regulation of nanoscale structures. ${ }^{10}$ Material synthesis with the knowledge of nanotechnology would be a powerful strategy to produce materials with desirable properties. Functional materials with necessary performances can be constructed from nanoscale units on the basis of the fusion of nanotechnology with other research fields such as organic chemistry, supramolecular chemistry, materials science, and bio-related technology. This task is taken by an emerging concept, nanoarchitectonics. ${ }^{11}$

As pioneered by Richard Feynman, nanotechnology opened plenty of scientific possibilities in the nanoscale bottom world. ${ }^{12}$ The rational construction of materials with regulated properties from nanoscale units can have further potentials in function developments as proposed by nanoarchitectonics, which was initiated by Masakazu Aono. ${ }^{13}$ The nanoarchitectonic approaches are supposed to produce functional materials using nanoscale units through combined and/or selected efforts of atom/molecular manipulation, organic synthesis, self-assembly/self-organization, micro-fabrication, and biorelated processes (Fig. 1A). ${ }^{14}$ These processes and effects work in harmony with nanoscale uncertainties such as thermal fluctuations. ${ }^{15}$ The contribution of multiple principles for construction is beneficial to architect hierarchical structures. ${ }^{16}$ The basic concept of nanoarchitectonics is general enough to be applied to various research fields such as sensors, ${ }^{17}$ catalysts, ${ }^{18}$ devices, ${ }^{19}$ energy-related applications, ${ }^{20}$ environmental issues, ${ }^{21}$ and biomedical problems. ${ }^{22}$ In addition to these practical fields, the nanoarchitectonics concept is effective in basic sciences including material synthesis, ${ }^{23}$ structure fabrications, ${ }^{24}$ and bio-related science. ${ }^{25}$

In this review article, the potentials of the nanoarchitectonic approach are discussed simply from the viewpoint of high capability of structure formation. It is demonstrated by the formation of materials with huge morphological variety from simple unit components, fullerenes $\left(\mathrm{C}_{60}\right.$ and $\left.\mathrm{C}_{70}\right)$, only through conventional lab-bench procedures (Fig. 1B). ${ }^{26}$ Fullerenes are zero-dimensional units made only from a single element component, carbon, although they and their derivatives have various functional possibilities in fundamental synthesis, ${ }^{27}$ electronic devices, ${ }^{28}$ and energy conversion. ${ }^{29}$ These fullerene molecules can be regarded as the simplest assembling components with respect to dimensionality, atomic variety, and electronic uniformity. Although the usual self-assembly processes are based heavily on the designs of the component structures, examples explained in this review article demonstrate that the nanoarchitectonics process itself is capable of producing a huge variety of fabricated products.

Nanoarchitectonic structures from fullerene molecules are first introduced according to dimensional classifications of one-dimensional, two-dimensional, and three-dimensional motifs in this review article. These processes are further extended to the formation of complicated morphologies and
(A) Nanoarchitectonics Concept

\begin{tabular}{|c|c|}
\hline Nanotechnology & $\begin{array}{l}\text { Organic Chemistry } \\
\text { Supramolecular Chemistry } \\
\text { Materials Science } \\
\text { Bio-Related Technology } \\
\text { etc }\end{array}$ \\
\hline
\end{tabular}

Atom, Molecule, and Nanomaterials

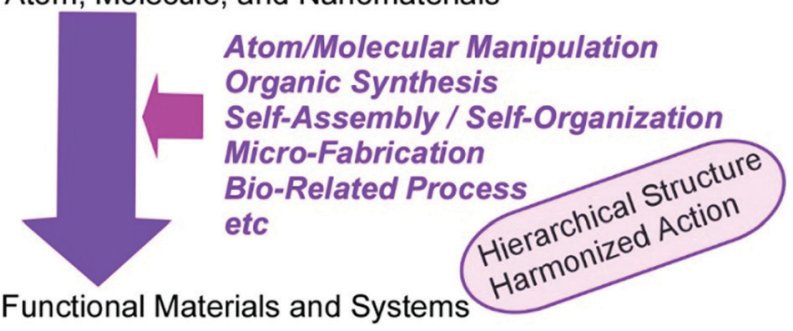

(B)

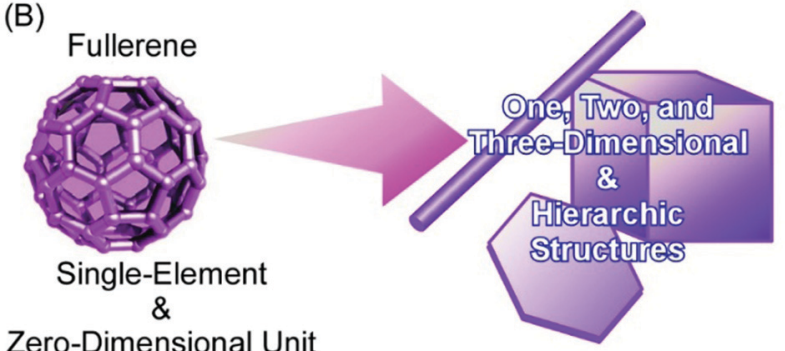

Zero-Dimensional Unit

Fig. 1 (A) Outline of nanoarchitectonics strategy for the preparation of functional materials and systems from atoms, molecules, and nanomaterials. (B) Fabrication of one-, two-, and two-dimensional materials and hierarchical structures from fullerenes as single-element and zerodimensional units.

hierarchical structures. In addition, a few novel applications of nanoarchitected fullerene materials are also described through showing their usages in (i) micro-scale material recognition and (ii) fate regulation of living cells.

\section{One-dimensional nanoarchitecture}

Structure formation with various morphologies from fullerene derivatives such as alkylated fullerenes has been reported. ${ }^{30}$ These molecules sometimes behave as amphiphiles in the appropriate media to form assemblies with particular shapes. Unlike these amphiphile-type assemblies, Miyazawa and co-workers developed a liquid-liquid interfacial precipitation method to fabricate crystalline assemblies of fullerene molecules themselves (mostly $\mathrm{C}_{60}$ and/or $\mathrm{C}_{70}$ ). ${ }^{31}$ Fullerene molecules are first dissolved in their good solvents onto which their poor solvents are gently added. Fullerene crystals with specific shapes are precipitated depending on the combinations between the good and poor solvents. This method often provides onedimensional fullerene assemblies, namely, nanowhiskers, nanofibers, nanowires, and nanotubes. The fabricated onedimensional structures of fullerene assemblies are sometimes converted into graphitic carbon objects and are decorated with 


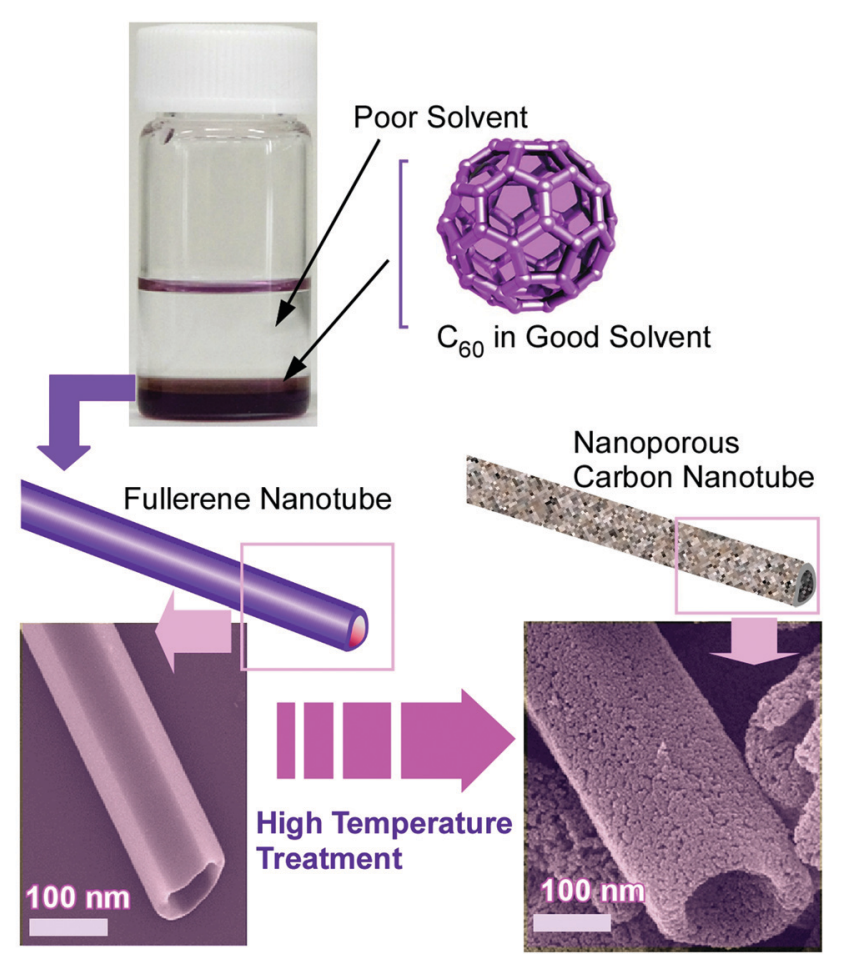

Fig. 2 Thermal conversion of one-dimensional crystalline $\mathrm{C}_{60}$ nanotubes into graphitic nanoporous carbon materials.

metal nanoparticles. Their utilization in electrochemical applications and sensors has also been investigated.

For example, the thermal conversion of one-dimensional crystalline $\mathrm{C}_{60}$ nanorods and nanotubes into graphitic nanoporous carbon materials was done with high-temperature treatments (up to $2000{ }^{\circ} \mathrm{C}$ ) under vacuum condition (Fig. 2). ${ }^{32}$ One-dimensional $\mathrm{C}_{60}$ nanorods and nanotubes were first obtained through precipitation at the interface between mesitylene and tert-butyl alcohol for nanorods or isopropyl alcohol for nanotubes. They were then subjected to the hightemperature process. Although the high-temperature process destroyed fullerene molecular structures, one-dimensional assembled motifs were maintained during the carbonization process. A detailed structural observation by a transmission electron microscope (TEM) revealed the formation of numerous nanopore structures (approximately size of $40-50 \mathrm{~nm}$ ) on the surfaces of the prepared carbon structures. Furthermore, the conversion of fullerene crystalline structures to graphitic motifs was proved by their Raman spectra. The graphitic nature with an enhanced effective surface area of the fabricated onedimensional carbon materials resulted in enhanced electrochemical performance and sensing capability to aromatic compounds. Quartz crystal microbalance (QCM) sensors coated with the fabricated carbon materials exhibited a higher sensitivity to aromatic gas substances such as benzene and toluene over aliphatic guests such as cyclohexane. The observed sensing selectivity could be based on the $\pi-\pi$ interaction between aromatic guest molecules and $\mathrm{sp}^{2}$-based graphitic frameworks of the carbon materials. This method provides an effective procedure to nanoarchitect $\pi$-electron-rich materials inevitably from a $\pi$-electron molecular source.

A similar thermal treatment at $2000{ }^{\circ} \mathrm{C}$ was applied for the conversion of fullerene $\mathrm{C}_{70}$ nanotubes into graphitic mesoporous carbon nanotubes. ${ }^{33}$ The obtained one-dimensional carbon materials possessed wall structures of mesoporous robust frameworks consisting of conjugated $\mathrm{sp}^{2}$ carbon. High capacitance was observed for the fabricated carbon materials on the basis of measurements by cyclic voltammetry and chronopotentiometry (charge-discharge). This nanoarchitectonics strategy using a $\pi$-electron carbon source is a rational way to fabricate electrochemical supercapacitors with high performances.

Composite structures of fullerene $\mathrm{C}_{60}$ nanorods decorated with silver nanoparticles were prepared through two-step processes (Fig. 3). ${ }^{34}$ The fullerene nanorods with an average diameter of $c a .200 \mathrm{~nm}$ and an average length of $c a .11 \mu \mathrm{m}$ were first fabricated at the interface between methanol and mesitylene. The addition of silver nitrate in ethanol and gentle growth of silver nanoparticles resulted in $\mathrm{C}_{60}$ nanorods decorated with silver nanoparticles. The nanoarchitected composites were plasmonic active and could work as substrates for highly sensitive surface-enhanced Raman scattering measurements.

Quasi-one-dimensional odd-shape fullerene $\left(\mathrm{C}_{60}\right)$ assemblies can be similarly fabricated. Nanoporous fullerene assemblies with bitter-melon-like shapes were prepared by quiet precipitation at

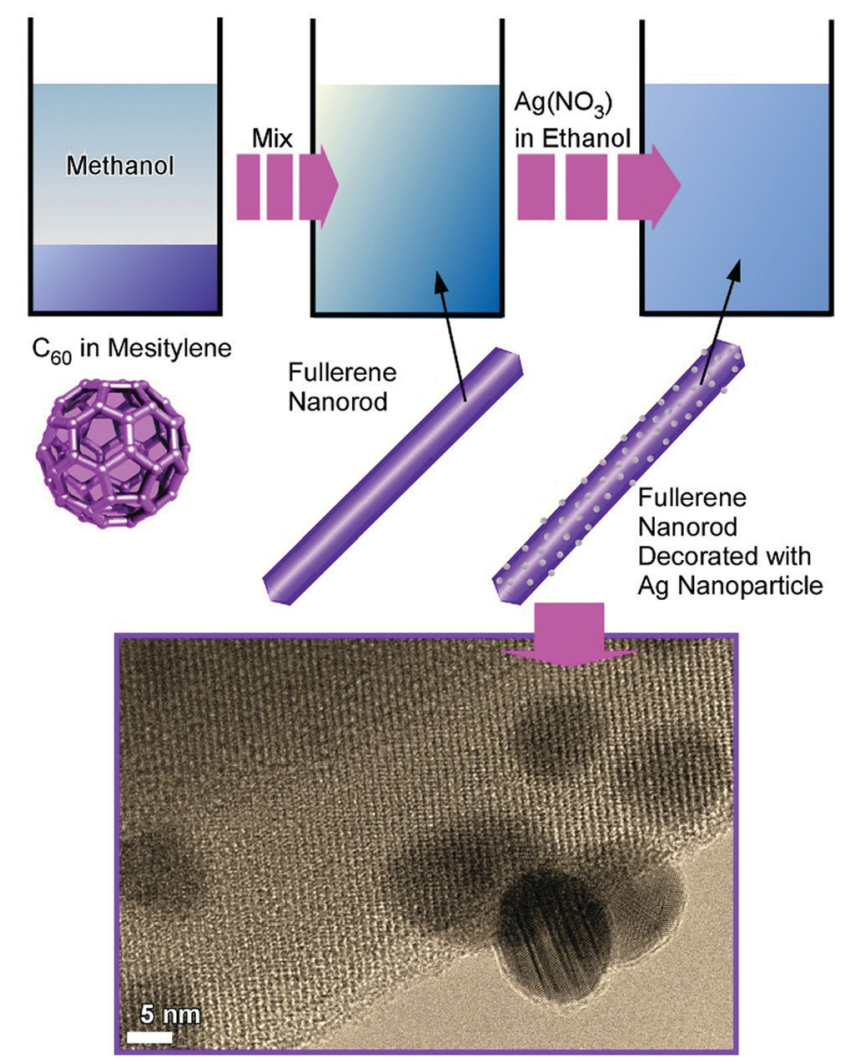

Fig. 3 Fabrication of composite structures of fullerene $C_{60}$ nanorods decorated with silver nanoparticles. 


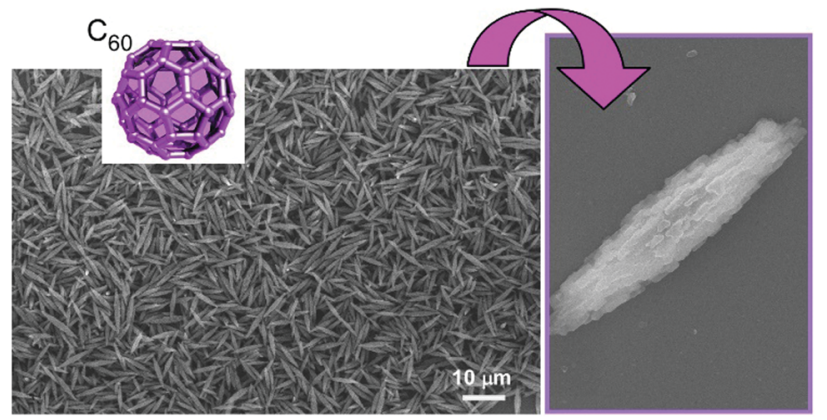

Fig. 4 Quasi-one-dimensional nanoporous fullerene assemblies with bitter-melon-like shape.

the interface between dodecylbenzene and isopropyl alcohol (Fig. 4). ${ }^{35}$ Although the obtained objects had a rather odd shape, their basic crystalline structures (face-centered cubic, $f c c$ phase) and lattice parameters were similar to those of pristine fullerene $\mathrm{C}_{60}$ crystals, as confirmed by powder X-ray diffraction pattern measurement. The nanoporous feature was also confirmed by TEM observation. The latter structural aspect was advantageous for sensing properties as demonstrated by a QCM sensor coated with the bitter melon fullerene objects. The order of sensitivity (aniline $>$ toluene $>$ benzene $>$ ethanol $>$ hexane $>$ cyclohexane $>$ methanol $>$ water) again revealed high affinities for aromatic guests probably through favourable $\pi-\pi$ interaction.

\section{Two-dimensional nanoarchitecture}

Two-dimensional objects have been paid much attention as demonstrated through various functions using graphene and related compounds, ${ }^{36}$ transition metal dichalcogenide, ${ }^{37}$ and various nanosheets. ${ }^{38}$ Not limited to the exfoliation method with multilayer materials, self-assembly and chemical reactions provide opportunities for the bottom-up production of twodimensional materials. Various examples including twodimensional patterned molecular films, ${ }^{39}$ two-dimensional metal-organic frameworks (MOFs) ${ }^{40}$ and covalent organic frameworks (COFs) ${ }^{41}$ carbon nanosheet from carbon nanoring by vortex Langmuir-Blodgett method, ${ }^{42}$ and spontaneously formed protein nanosheets capable of controlling deferrization of stem cells ${ }^{43}$ have been investigated at liquid interfaces. As seen in these examples, two-dimensional liquid interfaces are media appropriate for the fabrication of two-dimensional materials. ${ }^{44}$ This idea can be applied to the preparation of fullerene-based two-dimensional nanoarchitectures.

For example, the fabrication of two-dimensional hexagonal nanosheets of $\mathrm{C}_{60}$ molecules was first found by Sathish and Miyazawa who prepared $\mathrm{C}_{60}$ hexagon nanosheets at the interface between toluene and isopropyl alcohol. ${ }^{45}$ Further research revealed that the appropriate selection of interface-forming solvents leads to the variation of shapes and dimensionalities of fullerene assemblies (Fig. 5). ${ }^{46}$ Various two-dimensional $\mathrm{C}_{60}$ assemblies can be formed simply through the addition of poor solvents such as tert-butyl alcohol and isopropyl alcohol to saturated $\mathrm{C}_{60}$ solutions of good solvents such as benzene,

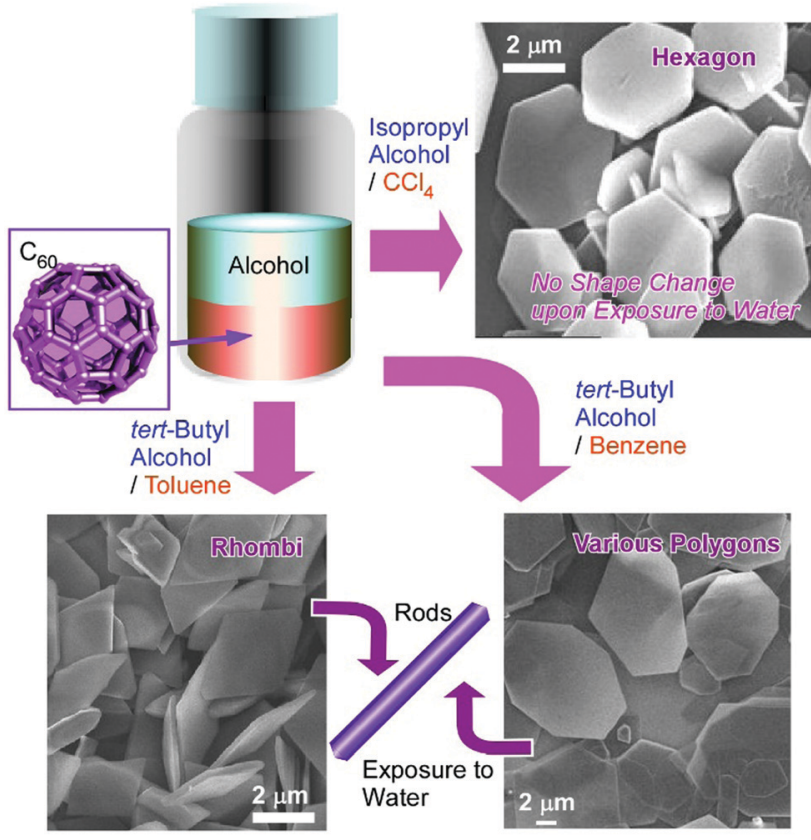

Fig. 5 Preparation of various two-dimensional fullerene assemblies.

toluene, $m$-xylene, $\mathrm{CCl}_{4}$, and $\mathrm{CS}_{2}$. In addition to the formation of hexagonal $\mathrm{C}_{60}$ nanosheets at interfaces between toluene and isopropyl alcohol, two-dimensional nanosheets with uniform rhombi and hexagonal shapes were obtained through the assembly of $\mathrm{C}_{60}$ molecules at tert-butyl alcohol/toluene interface and isopropyl alcohol/ $\mathrm{CCl}_{4}$ interface, respectively. Twodimensional polygon mixtures of $\mathrm{C}_{60}$ assemblies were formed at the interface between tert-butyl alcohol and benzene. The crystalline lattices favourably formed for these two-dimensional objects are probably the most influential factors that determine the shapes of the two-dimensional objects. With some stimuli such as contact with water, the two-dimensional rhombi objects were transformed into one-dimensional nanorods through rolling-up motion. The latter transformation was driven by the release of high surface energy.

Pore-engineering within two-dimensional objects was achieved by faint adjustments of solvent systems at the liquidliquid interfacial precipitation. Two-dimensional nanosheets possessing bimodal macroporous/mesoporous structures were fabricated through $\mathrm{C}_{60}$ assembly at interfaces between isopropyl alcohol and $\mathrm{CCl}_{4} /$ benzene mixtures (Fig. 6). ${ }^{47}$ At high contents of $\mathrm{CCl}_{4}$, macropores were formed on the two-dimensional nanosheets (crystalline sheet size of $c a .5 \mu \mathrm{m}$ and thickness of 0.8 to $1 \mu \mathrm{m}$ ). In addition, smaller mesopores were also formed within the macropores at appropriate mixing conditions between $\mathrm{CCl}_{4}$ and benzene. The average sizes of mesopores were tuned to be 15 to $25 \mathrm{~nm}$ and 20 to $40 \mathrm{~nm}$ at mixing ratios of $\mathrm{CCl}_{4} /$ benzene at $80: 20$ and 90:10, respectively. The latter bimodal structures were accompanied by mixed $f c c$ and $h c p$ crystalline structures. It is supposed that the evaporation of solvents entrapped within these could be the origin of mesopore formation. The formed bimodal nanoarchitectures had high 


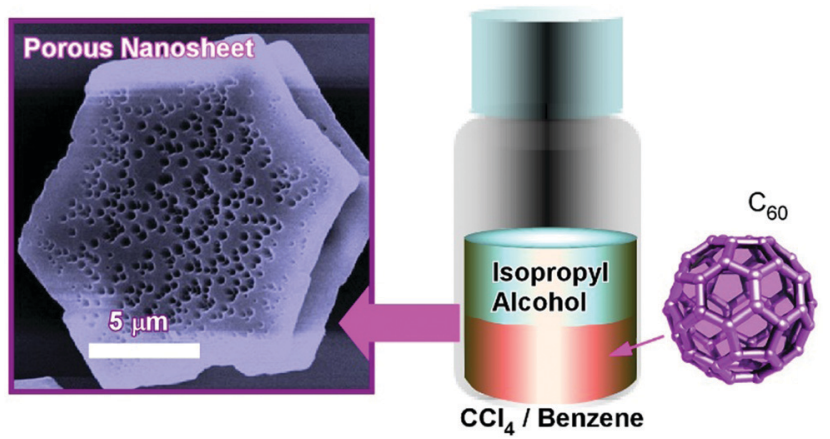

Fig. 6 Fabrication of two-dimensional nanosheet possessing bimodal macroporous/mesoporous structures.

surface areas with enhanced electrochemical activities, which could be useful for energy-related applications.

Pore-formation on two-dimensional $\mathrm{C}_{60}$ structures can be achieved through heat treatment at a quite high temperature as demonstrated in the fabrication of a mesoporous quasi-twodimensional carbon microbelt from the corresponding twodimensional $\mathrm{C}_{60}$ microbelt (Fig. 7). ${ }^{48}$ In the first step, two-dimensional microbelts were prepared from $\mathrm{C}_{60}$ molecules at the interface between isopropyl alcohol and $\mathrm{CS}_{2}$ with a certain incubation time. The formed two-dimensional $\mathrm{C}_{60}$ assemblies were carbonized at ultra-high temperatures such as 900 and $2000{ }^{\circ} \mathrm{C}$ under a constant flow of nitrogen gas $\left(120 \mathrm{~cm}^{3} \mathrm{~min}^{-1}\right)$ at a heating speed of $5{ }^{\circ} \mathrm{C} \mathrm{min}^{-1}$ into two-dimensional nanocarbon materials. The two-dimensional carbon microbelts fabricated through the high-temperature treatment exhibited excellent electrochemical supercapacitive performance with high cyclic stability without any capacitance loss. The mesoporous carbon microbelts had hierarchical bimodal pore structures that are advantageous for storage and rapid ion transport throughout the carbonaceous matrix.

Recently, Choi and co-workers reported an interesting example of fullerene two-dimensional objects, flower-shaped crystals with six symmetric petals, from $\mathrm{C}_{60}$ and $\mathrm{C}_{70}$ dissolved in mesitylene (Fig. 8). ${ }^{49}$ This interesting shape is supposed to follow the first nucleation of $\mathrm{C}_{70}$ with six-fold symmetry with co-crystallization of both $\mathrm{C}_{60}$ and $\mathrm{C}_{70}$ molecules. In the initial stage, a pure $\mathrm{C}_{70}$ crystal was grown that was followed by the two-dimensional growth of crystals upon attachment of $\mathrm{C}_{60}$ molecules to the lateral ends of the initially created $\mathrm{C}_{70}$ seed.

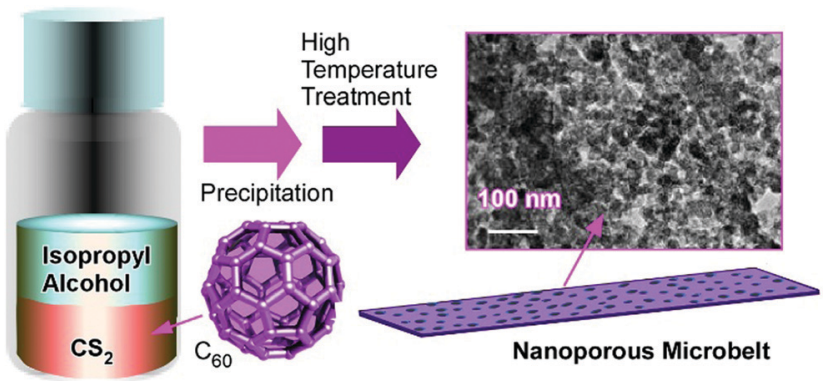

Fig. 7 Fabrication of mesoporous quasi two-dimensional carbon microbelt.

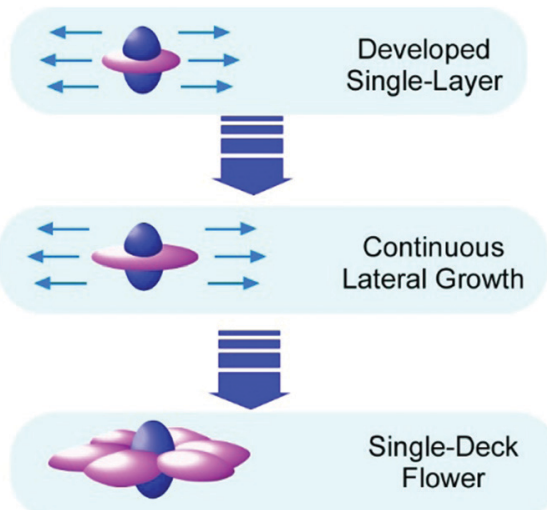

Fig. 8 Growth of fullerene two-dimensional objects, flower-shaped crystals with six symmetric petals.

The fabrication of non-crystalline two-dimensional fullerene films was demonstrated using the electrochemical coupling of electroactive carbazole and pyrene units attached to a fullerene molecule. ${ }^{50}$ This strategy provided amorphous and fullerene rich two-dimensional films. The prepared films had transparent features and exhibited good photoactivity with a significant optical-limiting response.

\section{Three-dimensional nanoarchitecture}

The capabilities of spontaneous self-assembling processes are not limited to the formation of low-dimensional objects of fullerene assemblies. The formation of three-dimensional nanoarchitectures and their hierarchical structures from zerodimensional molecular fullerene units is also an active research target of nanoarchitectonics. For example, the fabrication of cubic-shaped assemblies from $\mathrm{C}_{70}$ molecules was pioneeringly reported by Choi and co-workers. ${ }^{51}$

\section{Fullerene cube}

The formation of three-dimensional cubic structures and their conversion to hierarchical nanoarchitectures was also demonstrated on the basis of the crystallization and decomposition of $\mathrm{Ag}(\mathrm{I})$-fullerene heteronanostructure (Fig. 9) ${ }^{52}$ Cubic crystalline structures of the Ag(I)-fullerene complex in tens-of-micron-size were formed at the interface of $\mathrm{C}_{60}$ benzene solution and silver(I) nitrate ethanol (or other alcohols) solution. The formed cubic structures possessed a tetragonal space group of $P 4_{2} / \mathrm{nmc}$. Upon exposure of the cubic $\mathrm{C}_{60}$-fullerene- $\mathrm{Ag}(\mathrm{I})$ organometallic crystals to aliphatic alcohols such as 1-butyl alcohol and isopropyl alcohol, a transformation from smooth-faced cubic structures to cube-shaped interpenetrated networks of needlelike crystals was induced. The needle-like one-dimensional structures were made of pristine $\mathrm{C}_{60}$, which was formed through the removal of $\mathrm{Ag}(\mathrm{I})$ ions from the original complexes. These integrated cubic structures were named as Bucky cubes. The sparing washing process with aliphatic alcohols resulted in the formation of cubic structures integrated with nanocomposites with $\mathrm{C}_{60}$ nanorods and silver nanoparticles. Theses composite 


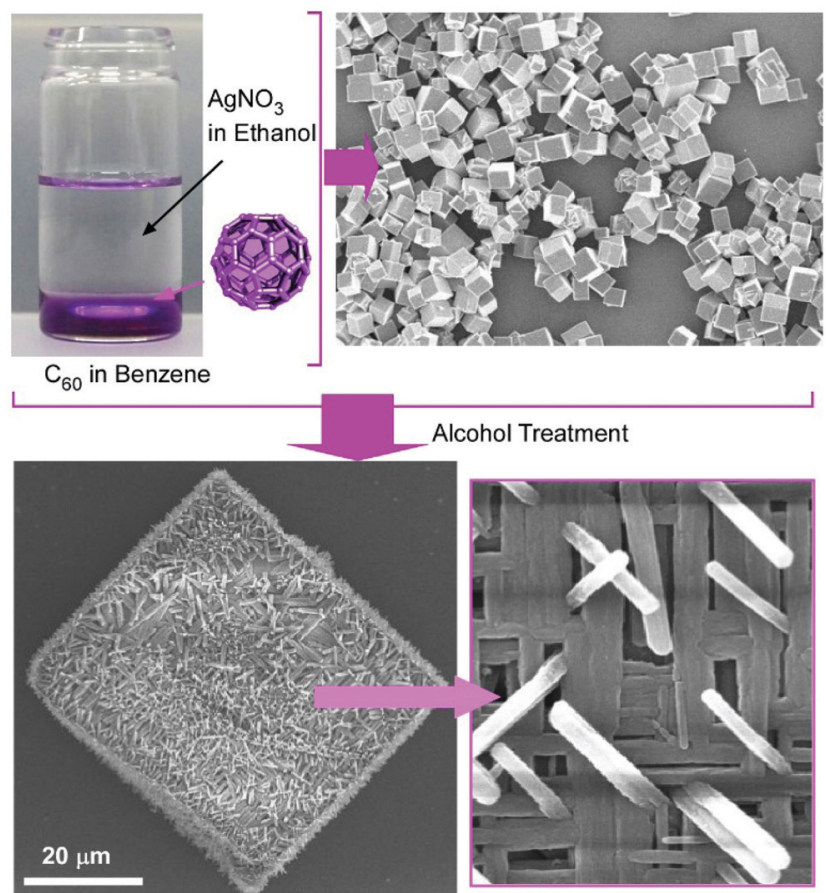

Fig. 9 Formation of three-dimensional cubic structures and their conversion to hierarchical nanoarchitectures (Bucky cubes) based on crystallization and decomposition of $\mathrm{Ag}(\mathrm{I})$-fullerene heteronanostructure.

cubic structures were demonstrated to have high activities in surface-enhanced Raman scattering (SERS) measurement for a trace amount of organic analyte.

At an appropriate interfacial environment, three-dimensional cubic structures were fabricated from another fullerene molecule, $\mathrm{C}_{70}$, without the assistance of metal ions. ${ }^{53}$ Fullerene $\mathrm{C}_{70}$ cubes were prepared through crystallization at the interface between tertbutyl alcohol and mesitylene. The fullerene cubes formed at room temperature were then converted into mesoporous fullerene cubes with heat treatment at $75{ }^{\circ} \mathrm{C}$ and casting on a solid substrate. In the incubation process at $75{ }^{\circ} \mathrm{C}$, the fullerene assemblies were first converted to an unstable nanorod intermediate that was further converted to mesoporous $\mathrm{C}_{70}$ cubes upon solvent evaporation. The re-formed fullerene cubes with a size of $c a .800 \mathrm{~nm}$ possessed mesoporous nanoarchitectures with a pore diameter of $c a .24 \mathrm{~nm}$. The fabricated mesoporous $\mathrm{C}_{70}$ cubes exhibited enhanced photoluminescent capability probably because of the high crystallinity of $\mathrm{C}_{70}$ molecules at the pore walls, and their mesoporous natures are advantageous for electrochemical activities.

The mesoporous fullerene $\left(\mathrm{C}_{70}\right)$ cubes can also be converted into mesoporous carbon materials by high-temperature treatments under inert gas condition. Carbonization at $900{ }^{\circ} \mathrm{C}$ gave mesoporous carbon materials, preserving their cubic structures and mesoporous features. ${ }^{54}$ Higher temperature conditions such as $2000{ }^{\circ} \mathrm{C}$ promoted the graphitization of carbon frameworks, but it was accompanied by the partial degradation of the mesoporous cubic structures. The former mesoporous carbon cubes especially exhibited a nice capacitive performance with

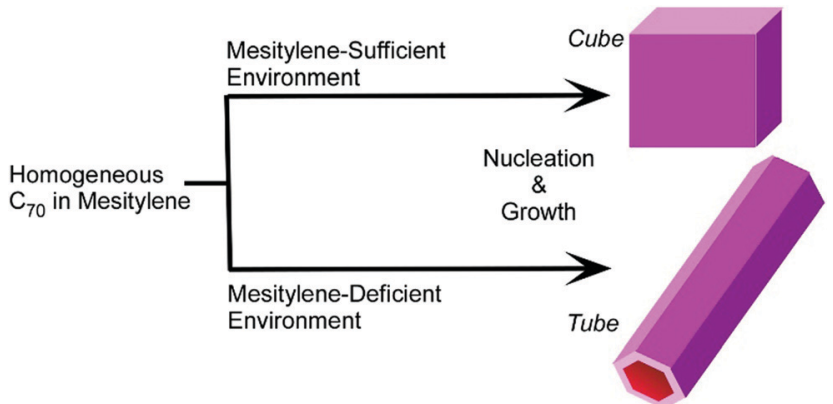

Fig. 10 Selective growth between three-dimensional $C_{70}$ cubes and onedimensional $\mathrm{C}_{70}$ tubes fabricated through re-precipitation from mixed solvent systems of isopropyl alcohol and mesitylene.

long cyclic stability because of well-developed mesoporous nanoarchitectures with highly active surface area.

Kim et al. revealed the fundamental aspects of selective growth between three-dimensional $\mathrm{C}_{70}$ cubes and one-dimensional $\mathrm{C}_{70}$ tubes that were fabricated through re-precipitation from mixed solvent systems of isopropyl alcohol and mesitylene (Fig. 10). ${ }^{55}$ The fabricated objects had different amounts of mesitylene molecules in their lattices, i.e., ratios of $\mathrm{C}_{70}$ to mesitylene were 1:2 in the case of $\mathrm{C}_{70}$ cubes and 1:0.7 for $\mathrm{C}_{70}$ tubes. The crystallization pathways for these $\mathrm{C}_{70}$ objects could be determined by the amount of mesitylene molecules near the $\mathrm{C}_{70}$ molecules, which depends on the mixing volume ratios between isopropyl alcohol and mesitylene.

\section{Other three-dimensional structures}

The addition of appropriate surfactants to the processes of fullerene crystallization at liquid-liquid interface sometimes causes the transformation of low-dimensional fullerene assemblies into shape-complicated three-dimensional nanoarchitectures. One-dimensional nanorods were obtained upon $\mathrm{C}_{60}$ assembly at the interface between isopropyl alcohol and ethylbenzene. The addition of only $1 \%$ of surfactants such as diglycerol monolaurate and monomyristate resulted in Konpeito-like three-dimensional crystals with an average diameter of $c a .1 .2 \mu \mathrm{m} .{ }^{56}$ The additive surfactant induced the modification of faceted rod morphology into $\mathrm{C}_{60}$ cluster aggregates as three-dimensional structures. The formed Konpeito-like crystals showed enhanced photoluminescent activity with a significant blue shift. In the case of cluster-type structures, graphitization at $2000{ }^{\circ} \mathrm{C}$ was harmless for morphology maintenance. Therefore, high electrochemical performances were achieved by heat-treatment at $2000{ }^{\circ} \mathrm{C}$.

$\mathrm{Lu}$, Tsukagoshi, and co-workers systematically investigated the formation of three-dimensional polyhedral microcrystals of $\mathrm{C}_{60}$ molecules (Fig. 11). ${ }^{57}$ By re-precipitation process from solvent systems of $n$-heptanol and aromatic solvents ( $p$-xylene, toluene, or ethylbenzene) with modulated solvent ratios, well-faceted parallelepiped, hexagonal plate, cuboctahedral, or octahedral $\mathrm{C}_{60}$ crystals with varying degrees of edge- and corner-truncation were obtained. As the ratio of $n$-heptanol gradually increased, the crystallization process changed from 


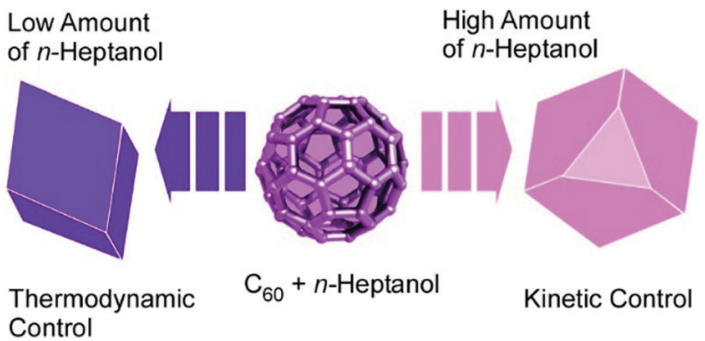

Fig. 11 Formation of three-dimensional polyhedral microcrystals of $C_{60}$ molecules by re-precipitation process from solvent systems of $n$-heptanol and aromatic solvents ( $p$-xylene, toluene, or ethylbenzene) with modulated solvent ratios.

thermodynamic to kinetic regime, which created a huge variety of three-dimensional polyhedral shapes. The prepared threedimensional objects could be useful for organic-moleculebased optoelectronic devices.

Shape control of three-dimensional $\mathrm{C}_{60}$ assemblies can be done simply by the addition of water as demonstrated by Piao, Guldi, and co-workers. ${ }^{58}$ The addition of water to isopropyl alcohol in the liquid-liquid interfacial precipitation process suppressed the charge transfer processes between electron-accepting fullerene and electron-donating solvents in the partner phase ( $n$-methyl-2-pyrrolidone, pyridine, and aniline). This effect is supposed to modify the morphologies of $\mathrm{C}_{60}$ assemblies from one-dimensional fibers to three-dimensional particles. In addition, this mechanism can be applied to control the activation and deactivation of charge-transfer interactions in fullerene assemblies, which could be useful for applications in optoelectronic devices including photo-detectors, lightemitting devices, and solar cells.

As unique three-dimensional objects, cone-shaped $\mathrm{C}_{60}$ assemblies were fabricated by Raston and co-workers, ${ }^{59}$ while similar cone structures from fullerene derivatives were previously reported by Nakanishi $e t$ al. ${ }^{60}$ The fabrication of cone-shaped $\mathrm{C}_{60}$ assemblies by Raston and co-workers was based on micro-mixing of $\mathrm{C}_{60} O$-xylene solution with $N, N$-dimethylformamide under continuous flow in a vortex fluidic device (Fig. 12). Although the $\mathrm{C}_{60}$ cones had to be prepared at well-selected conditions and solvent selections, the process was scalable. It was reported that $4.2 \mathrm{mg}$ of the $\mathrm{C}_{60}$ cones was produced by passing $40 \mathrm{~mL}$ of the two solutions through the vortex fluidic device.

\section{Hierarchical nanoarchitecture}

As partially introduced in the previous section, structural transformation after the primary assembling processes often results in the formation of hierarchical structures (structure-instructure). Some examples of the formation of hierarchical nanoarchitectures from fullerene units $\left(\mathrm{C}_{60}\right.$ or $\left.\mathrm{C}_{70}\right)$ are introduced in this section.

\section{Crystal transformation for hierarchical structure}

Hierarchical structures including features of microcubes, nanorods, and mesopores (fullerene cubes composed of mesoporous

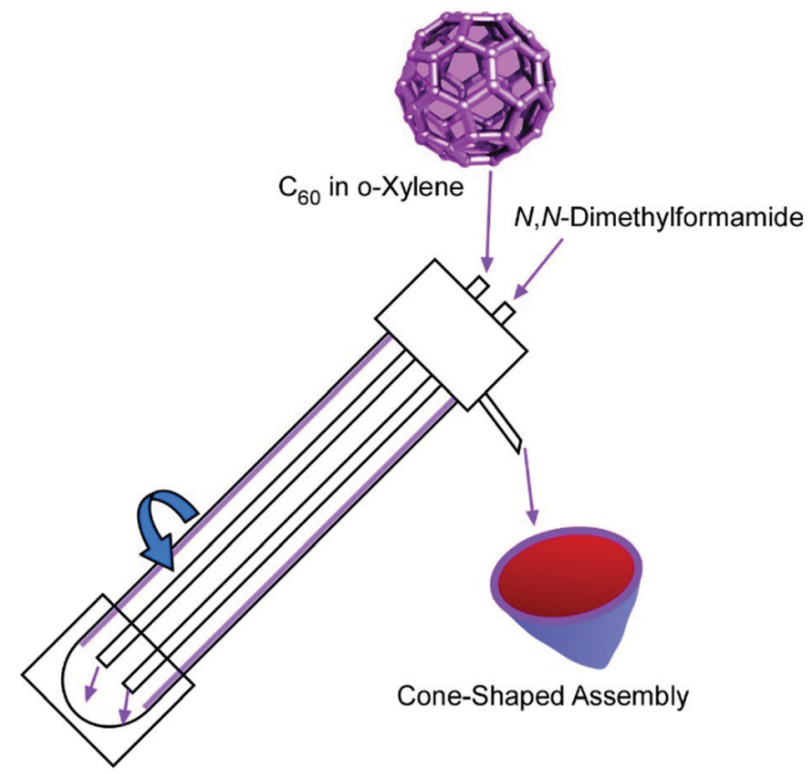

Fig. 12 Fabrication of cone-shaped $\mathrm{C}_{60}$ assemblies based on micro-mixing of $\mathrm{C}_{60} \mathrm{O}$-xylene solution in $\mathrm{N}, \mathrm{N}$-dimethylformamide under continuous flow in vortex fluidic device.

nanorods) were formed through the interfacial assembly of $\mathrm{C}_{70}$ molecules and subsequent solvent treatment (Fig. 13). ${ }^{61}$ The original $\mathrm{C}_{70}$ microcubes were first synthesized through an ultrasound-assisted process for the precipitation of $\mathrm{C}_{70}$ molecules at the interface between mesitylene and tert-butyl alcohol followed by the application of mild sonication and incubation. The obtained microcubes with smooth surfaces were exposed to isopropyl alcohol with gentle shaking. This process induced the growth of nanorods from the surfaces of the microcubes. The nanorods grew mostly perpendicular to the faces of the microcubes. Interestingly, the direction of nanorod growth became parallel to the faces of the microcubes if the shaking was avoided. These results suggested that the direction of nanorod growth was governed by the diffusion kinetics of isopropyl alcohol and/or $\mathrm{C}_{70}$ molecules. A detailed observation further revealed the presence of the mesoporous features of the nanorods, finally resulting in cube-rod-mesopore hierarchical structures. Especially, the structural motif of the porepossessing antenna structures of fullerene $\mathrm{C}_{70}$ is advantageous for the detection of gaseous guests. A QCM sensor coated with a hierarchical $\mathrm{C}_{70}$ cube exhibited excellent detection affinity to aromatic gasses such as toluene and pyridine. In addition, the formed hierarchical structures due to the high surface area showed enhanced electrochemical activity.

As two-dimensional hierarchical structures, Chen and co-workers successfully prepared two-dimensional $\mathrm{C}_{60}$ nanomesh structures based on faint solvent tuning (Fig. 14). ${ }^{62}$ In their strategy, hexagonal nanosheets of $\mathrm{C}_{60}$ assembly were first prepared in a mixed solvent of $\mathrm{CCl}_{4}$ and $m$-xylene mixture. The precipitate solution was then exposed to air to induce solvent evaporation. Since $\mathrm{CCl}_{4}$ vaporized quicker than $m$-xylene, the formation of nanorods within hexagonal nanosheets with an $m$-xylene-rich condition was induced. Although the transformation 

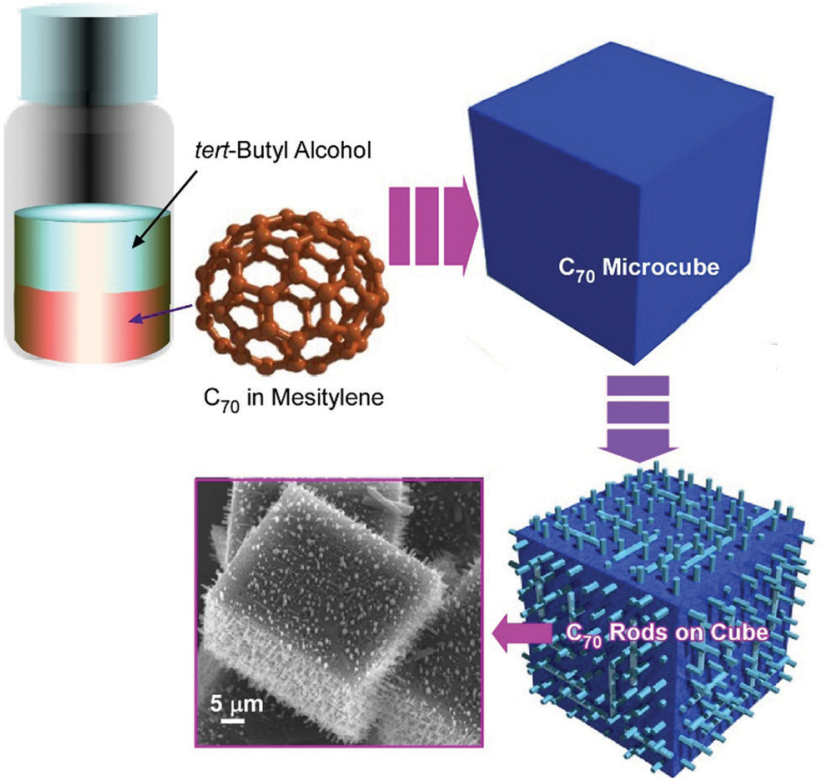

Fig. 13 Formation of hierarchical structures including features of microcubes, nanorods, and mesopores (fullerene cubes composed of mesoporous nanorods) through the interfacial assembly of $C_{70}$ molecules and subsequent solvent treatment.
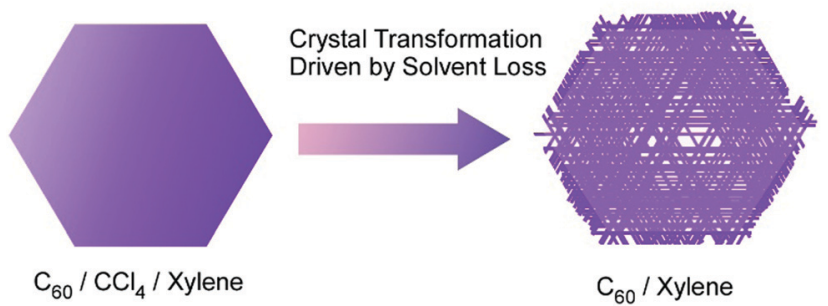

$\mathrm{C}_{60} /$ Xylene

Fig. 14 Preparation of two-dimensional $\mathrm{C}_{60}$ nano-mesh structures based on crystalline transformation through solvent composition change.

to one-dimensional nanorods was promoted, the entire hexagonal shape was maintained. As a result, hierarchical structures, hexagonal nanosheets with internal mesh structures, were finally formed accompanied by the transformation of the crystalline lattice from the $f c c$ sheet to the $h c p$ rod.

Tachibana and co-workers also reported the formation of a two-dimensional hierarchical $\mathrm{C}_{60}$ assembly, rods-in-hexagon, with detailed in situ observation (Fig. 15). ${ }^{63}$ Hexagonal nanosheets of $\mathrm{C}_{60}$ molecules were first prepared with a mixture of $\mathrm{CCl}_{4}$ and toluene. First, the evaporation of $\mathrm{CCl}_{4}$ and enrichment of toluene content induced the dissolution of $\mathrm{C}_{60}$ molecules within a hexagonal frame. Further, the evaporation of toluene resulted in the re-crystallization of $\mathrm{C}_{60}$ to form nanorods. The long axes of the re-crystallized nanorods aligned in parallel to one of the edges of the original hexagonal frame. This dissolution and re-crystallization of $\mathrm{C}_{60}$ molecules upon changes in solvent composition and concentrations finally resulted in the two-dimensional hierarchical rods-in-hexagon structures.

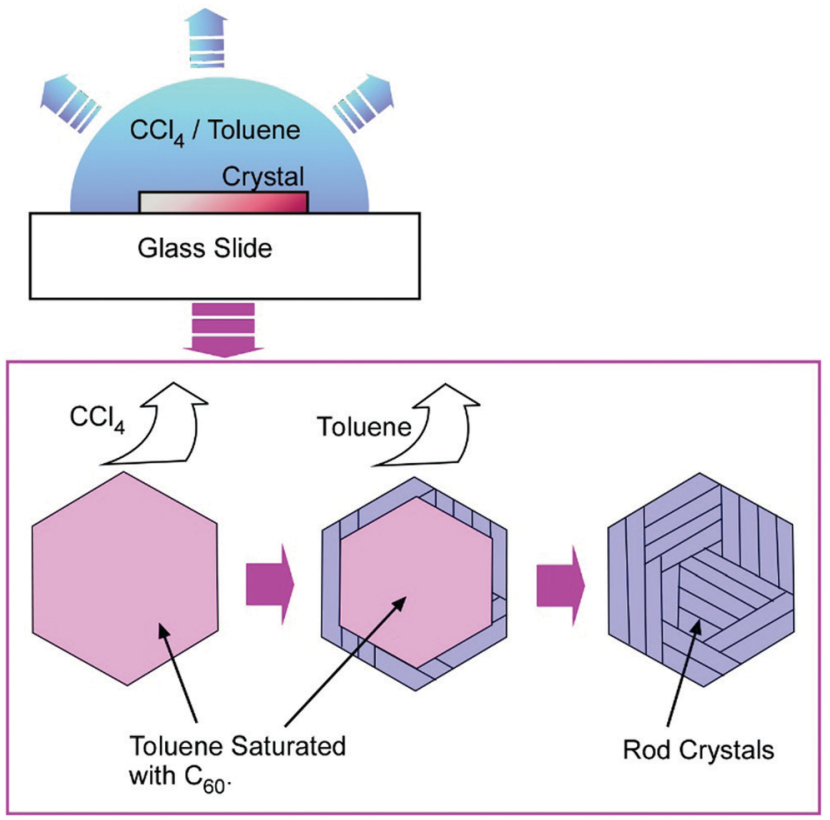

Fig. 15 Formation of two-dimensional hierarchical $C_{60}$ assembly, rodsin-hexagon, by solvent composition changes through solvent evaluation.

\section{Shape shifter for supramolecular differentiation}

Shape-shifting behaviours of three-dimensional fullerene assemblies were also reported. The time-programmed mechanisms of shape-shifting can be likened to biological metamorphosis during differentiation processes (Fig. 16). This non-biocomponent differentiation mimics can be regarded as supramolecular differentiation. ${ }^{64}$ Phase separation at interfacial media and selective growth of assembled structures from two $\mathrm{C}_{60}$ fullerene derivatives,

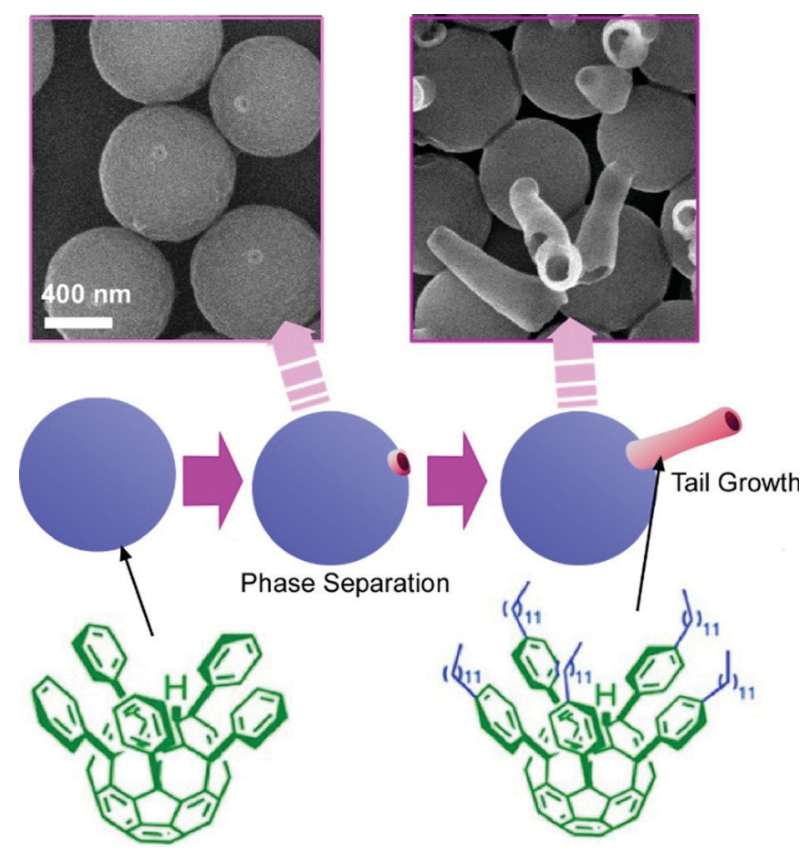

Fig. 16 Time-programmed mechanism of shape-shifting of assemblies of fullerene derivatives as supramolecular differentiation. 
pentakis(phenyl)fullerene and pentakis(4-dodecylphenyl)fullerene), followed by homogeneous self-assembly, led to the supramolecular differentiation phenomena like the transformation from eggs to tadpoles in frogs. The co-assembly of these two fullerene components at the interface between isopropyl alcohol and toluene provided egg-like spherical structures. Phase separation of an isolated patch-like domain of pentakis(4-dodecylphenyl)fullerene) was induced on the spherical surface of the main body of pentakis(phenyl)fullerene. Transformation to the homogeneous assembly by the mixing of two systems upon sonication initiated tale growth with a tubular assembly of pentakis(4dodecylphenyl)fullerene) and caused shape-shifting to tadpoles. Only one single pentakis(4-dodecylphenyl)fullerene) tail could be developed from one separated domain. The number of phaseseparated patch domains had time-dependent features and thus the number of grown tales was determined by the timing of transformation to homogeneous assembly modes. The final shapes of egg-tail assembly were quite dependent on the timing of the processes. Of course, all these processes including selfassembly and phase-separation are processes without any use of biological components. This example strikingly indicates that a series of fundamental physico-chemical events can mimic a biological phenomenon, biological metamorphosis as a differentiationlike process.

Recently, Chen and co-workers reported an interesting method for shape-shifting fullerene assemblies to produce variously shaped hollow fullerene nanoarhitectures. ${ }^{65}$ Their innovative method is based on the liquid-template concept. Liquid-liquid interfaces for fullerene assemblies are not limited to visible macroscopic two-dimensional interfaces, and templates for fullerene assemblies are not limited to solid materials. Based on these thoughts, shape-changeable liquid droplets were used for assembling media for $\mathrm{C}_{60}$ molecules (Fig. 17). In their fabrication, $\mathrm{C}_{60} m$-xylene solution was added to $N, N$-dimethylformamide with vortex and then isopropyl alcohol was added to decrease the solubility of $\mathrm{C}_{60}$ molecules. This process resulted first in bowl-shaped hollow $\mathrm{C}_{60}$ hemispheres that were shape-shifted to spheres with tube-like protrusions upon prolonged incubations. Due to the flexible shape-shifting nature of the $m$-xylene liquid template, a variety of hollow $\mathrm{C}_{60}$ nanostructures including bottle-shaped hollow objects and multi-compartment vessels could be synthesized under welldesigned processes. Their strategy opens ways to architect interconnected hollow systems from an independent conventional hollow structure. Very recently, they have extended a

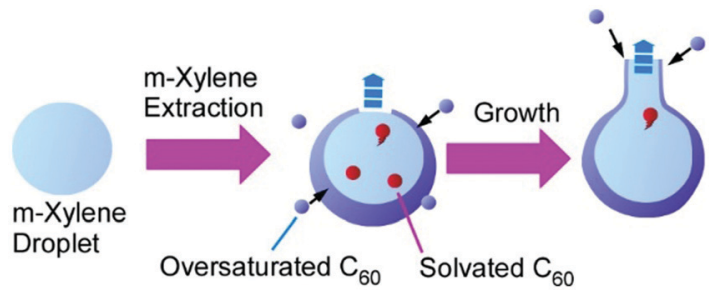

Fig. 17 Shape-shift from bowl-shaped hollow $C_{60}$ hemispheres to a sphere with a tube-like protrusion on shape-changeable liquid droplets. related technique to the method for the precise dimerization of hollow fullerene compartments. ${ }^{66}$

\section{Pore-engineering}

As seen in various porous materials such as mesoporous materials, ${ }^{67}$ metal-organic frameworks, ${ }^{68}$ and coordination polymers, ${ }^{69}$ pore-engineered materials have a huge variety of functions and applications on the basis of their regular nanospace geometries and enhanced active surface area. For example, Vinu and co-workers developed a method to synthesize mesoporous $\mathrm{C}_{70}$ materials via a hard-template approach. ${ }^{70}$ In their procedure, two-dimensional mesoporous silica, SBA-15, was used as the hard template (Fig. 18). Within mesoporous silica nanochannels, a highly concentrated solution of $\mathrm{C}_{70}$ molecules in chlorinated naphthalene was impregnated. Several steps including high-temperature $\left(900{ }^{\circ} \mathrm{C}\right)$ treatments induced crosslinking and polymerization of $\mathrm{C}_{70}$ molecules where chlorinated naphthalene assisted the molecular packing and polymerization of $\mathrm{C}_{70}$. The removal of the hard template by $\mathrm{NaOH}$ or $\mathrm{HF}$ finally provided ordered mesoporous $\mathrm{C}_{70}$ nanoarchitectures with crystalline pore walls. With their high active surface area with bimodal pore geometry, excellent properties of the oxygen reduction reaction for fuel cells and supercapacitors were confirmed. These pore-engineered fullerene-originated materials could also have high chances in applications such as catalysis and energy storage.

Very recently, a new chemical etching technique to selectively fabricate pore structures on one-dimensional fullerene $\mathrm{C}_{60}$ nanorods, two-dimensional fullerene $\mathrm{C}_{60}$ nanosheets, and three-dimensional fullerene $\mathrm{C}_{70}$ cubes has been reported (Fig. 19). ${ }^{71}$ These objects were first prepared by conventional liquid-liquid interfacial precipitation processes. These objects were etched by the addition of ethylene diamine whose high nucleophilicity induced an amination reaction with relatively electron-deficient fullerene molecules. The etching processes selectively occurred depending on the dimensionality of the fullerene assemblies. In the case of one-dimensional fullerene $\mathrm{C}_{60}$ nanorods, etching proceeded selectively at the end of the nanorod faces, and hollow nanotube structures were finally formed. The difference in reactivity and lattice stability might be origins of the observed etching selectivity. Preferential etching

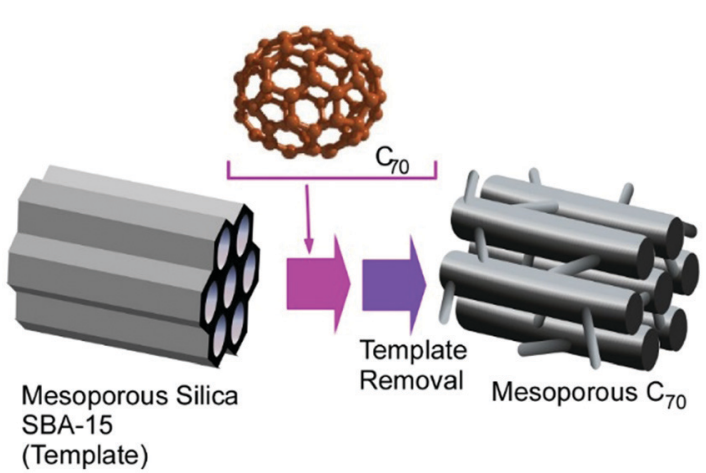

Fig. 18 Synthesis of mesoporous $C_{70}$ materials using two-dimensional mesoporous silica, SBA-15, as a hard template. 


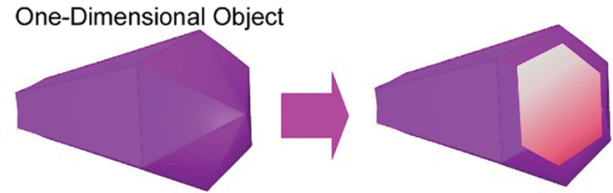

Two-Dimensional Object

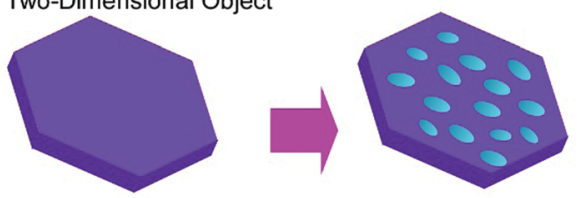

Three-Dimensional Object

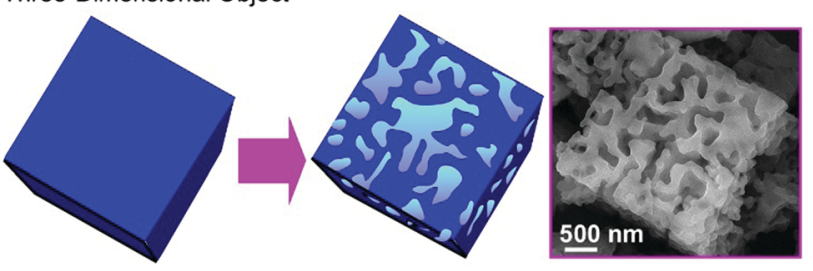

Fig. 19 Chemical etching to selectively fabricate pore structures on onedimensional fullerene $C_{60}$ nanorods, two-dimensional fullerene $C_{60}$ nanosheets, and three-dimensional fullerene $\mathrm{C}_{70}$ cubes.

occurred at upper and lower faces of two-dimensional $\mathrm{C}_{60}$ nanosheets, resulting in porous nanosheets. In contrast, etching proceeded from all the faces of three-dimensional cubes. Etching with three-dimensional $\mathrm{C}_{70}$ cubes resulted in three-dimensional objects with a gyroid-like morphology. The fabrication of the latter nanoarchitectures with a highly integrated structure would be tough with the conventional self-assembling processes. The etched objects are generally surface-modified with amino groups, and, therefore, the water-dispersibility of these objects becomes high. The etched objects have enhanced surface area and exhibit superior capabilities in sensing and energy applications as expected. These chemical etching processes apparently cost less compared with the usual physical lithographic techniques. The above-mentioned chemical etching technique can work as beaker lithography to provide well-integrated pore-engineered fullerene materials that could be useful in a wide range of applications including sensors, energy devices, drug carriers, and biomedical usages.

\section{Micro-function with fullerene nanoarchitecture}

Fullerene assemblies and their converted carbon materials have been used in many applications including energy-related usages, sensors, and drug deliveries. Their high-surface-area aspects, $\pi$-electron-rich nature, and sufficient hydrophobicity are mainly used in these applications. Not similar to the other carbon materials such as nanoporous carbon materials, the fullerene assembling materials often have microscopic or submicroscopic structural features. The latter features are advantageous for the interaction of microscopic objects. From this viewpoint, some functions specific to microscale objects such as microparticles and living cells are below exemplified as applications of the fullerene assembling materials.

\section{Micro-object recognition}

The recognition of molecules at interfaces and molecular cavities has been extensively investigated. For example, artificial molecular cavities such as crown ethers, cyclodextrins, and other cyclic hosts are often used to discriminate the appropriate guest molecules upon matching of size and shape together with the interaction of functional groups between the guest and cavity. ${ }^{72}$ Since some fullerene assembling materials have micron and/or submicron-sized pore geometries, these materials are suited for the discrimination of microscopic objects. For example, the selective recognition of submicron particles by hole-in-cube $\mathrm{C}_{70}$ assemblies was demonstrated. ${ }^{73}$ The hole-incube $\mathrm{C}_{70}$ assemblies having one hole (1-1.5 $\left.\mu \mathrm{m}\right)$ on every face of the cubic structure $(3.4 \pm 0.4 \mu \mathrm{m})$ were synthesized through precipitation using $\mathrm{C}_{70}$ molecules at mesitylene/tert-butyl alcohol system with a dynamic mixing process. The resulting cubic objects possessed one open hole structure at every face, and the holes could be intentionally closed and reopened by the addition of extra $\mathrm{C}_{70}$ molecules and electron beam irradiation, respectively. The hole-in-cube structures with open holes were subjected to the discrimination of two kinds of submicroparticles, resorcinolformaldehyde polymer resin particles and graphitic carbon particles (Fig. 20). Observations by scanning electron microscope (SEM) revealed that the holes in the cubes tend to be occupied by the graphitic carbon particles but the entrapment of the polymer-resin particles is limited. Although both the submicron particles are hydrophobic, the particles with graphitic surfaces were preferentially entrapped into the holes of the cubes of $\mathrm{C}_{70}$ molecules. The selective recognition of the graphitic carbon particles is probably based on favourable $\pi-\pi$ interaction between
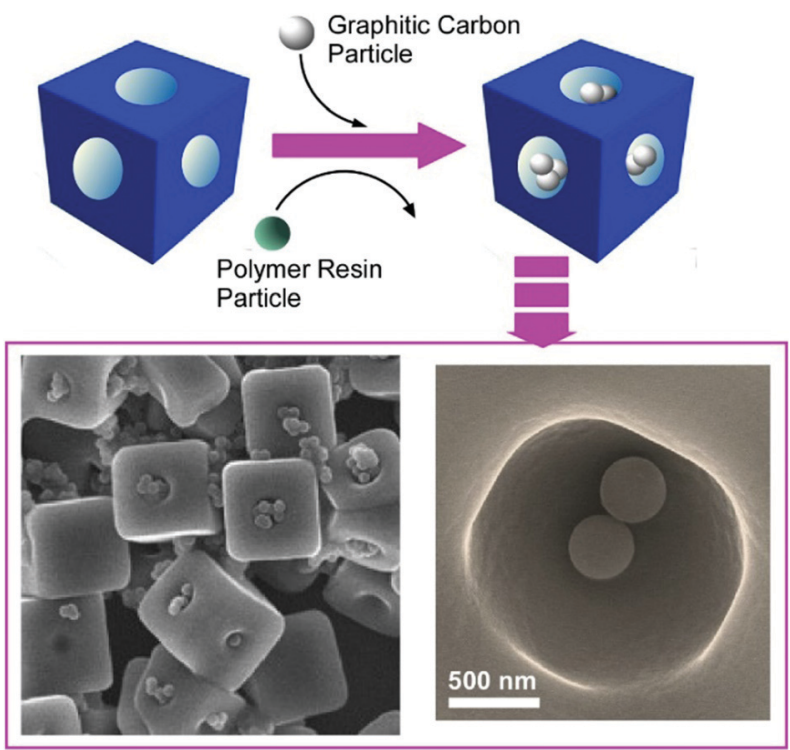

Fig. 20 The hole-in-cube $\mathrm{C}_{70}$ structure for discrimination of two-kinds of submicron particles, resorcinol-formaldehyde polymer resin particles and graphitic carbon particles. 
particles and surface of holes. This kind of recognition on a microscopic scale could be extended to many application opportunities including solving environmental problems such as toxic particle matter removal and in medical uses as drug carriers.

Similar to hole-in-cube structures of fullerene-related materials, Tian and Yang recently reported excellent work on the selected fabrication of cube and dice structures from several metal nitride cluster fullerenes. ${ }^{74}$ By just selecting appropriate ratios of mesitylene and isopropyl alcohol, these three-dimensional structures were selectively synthesized. Especially, the dice-shaped objects showed enhanced photoluminescence as compared with the corresponding cubes.

Very recently, a novel fullerene object, fullerene microhorns, was fabricated in situ through fullerene microtube structures. ${ }^{75}$ The precursor fullerene microtubes were spontaneously formed through the addition of tert-butyl alcohol into a mesitylene solution of $\mathrm{C}_{60}$ and $\mathrm{C}_{70}$ fullerene mixture. The structural transformation of the resulting fullerene microtubes into the fullerene microhorns was performed by the addition of a few drops of a tert-butyl alcohol/mesitylene mixture to the fullerene microtubes deposited on the surface of a silicon wafer and the subsequent slow solvent evaporation. Upon detailed observation, it was found that one fullerene microtube was broken into two fullerene microhorns within a few seconds. Dissolution by solvents selectively occurred in the middle region of the fullerene microtube to create two microhorns with half-length of the original fullerene microtube. This manipulable microscale hollow object, fullerene microhorn, was next subjected to the recognition of micron-sized objects. Among the examined microparticles, silica particles were preferentially entrapped and attached to the fullerene microhorns as compared with the other similar-sized particles such as fullerene $\mathrm{C}_{70}$ particles, polystyrene latex particles, hydroxylate particles, and carboxylate particles (Fig. 21). The zeta-potential measurement revealed that the zeta-potential of the fullerene microhorns

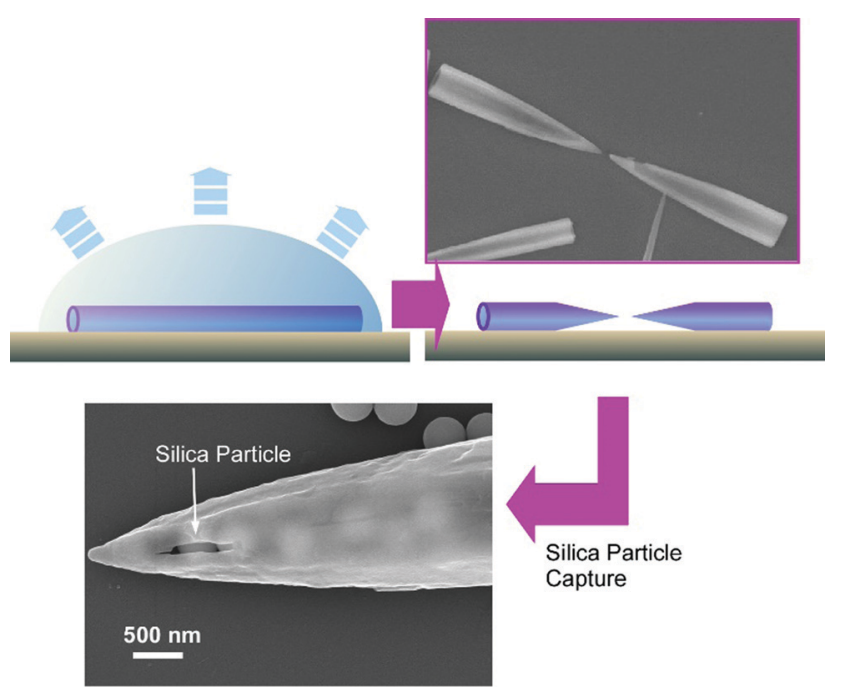

Fig. 21 The transformation from fullerene microtube to microhorn and their selective capture of silica particles. was negative $(-51.1 \mathrm{mV})$, and the silica nanoparticles had a positive value $(+1.2 \mathrm{mV})$ for the zeta-potential under the same condition. Electrostatic interaction has a crucial contribution in this selective particle recognition. Interestingly, the selectivity of microparticles is different between hole-in-cube and microhorns of fullerene assemblies. These fullerene objects can be selectively used depending on the type of application, such as toxic particle entrapment and bio-related particle carrier. Especially, the fullerene microhorns could be useful in smart selective drug/biomaterial delivery and transport-release of micron-sized bio-related objects.

\section{Fate control of living cell}

Another attractive research target in microscopic science is the regulation of living cell behaviours. Living cells sensitively perceive the viscoelastic features of the contacting material surfaces, which is widely studied in the field of mechanobiology. ${ }^{76}$ Since fullerene-based nanoarchitectures and microarchitectures have a rigid mechanical nature, their assemblies would provide interesting opportunities for the mechanical control of living cells. Although the high aspect ratio of one-dimensional nanocarbon materials such as carbon nanotubes may be suspected to have certain cytotoxicity, the aspect ratios of one-dimensional fullerene assemblies are not so high and thus they are bio-harmless. For example, the highly aligned two-dimensional assemblies of one-dimensional fullerene nanowhiskers fabricated by the conventional LB method ${ }^{77}$ and vortex LB methods ${ }^{78}$ are actually evaluated as platforms for the regulation of cell orientation and cell differentiation.

This strategy was recently applied to regulate human mesenchymal stem cells for their enhanced renewal capability and multipotency where aligned one-dimensional fullerene nanowhiskers o a solid surface worked as a large area scaffold for cell culture (Fig. 22). ${ }^{79}$ In this approach, fullerene nanowhiskers with different aspect ratios were first prepared at the interface between $m$-xylene and isopropyl alcohol by changing the speed of addition of isopropyl alcohol into $\mathrm{C}_{60} m$-xylene solution. The fabricated fullerene nanowhisker materials were then subjected to the LB process to produce highly aligned

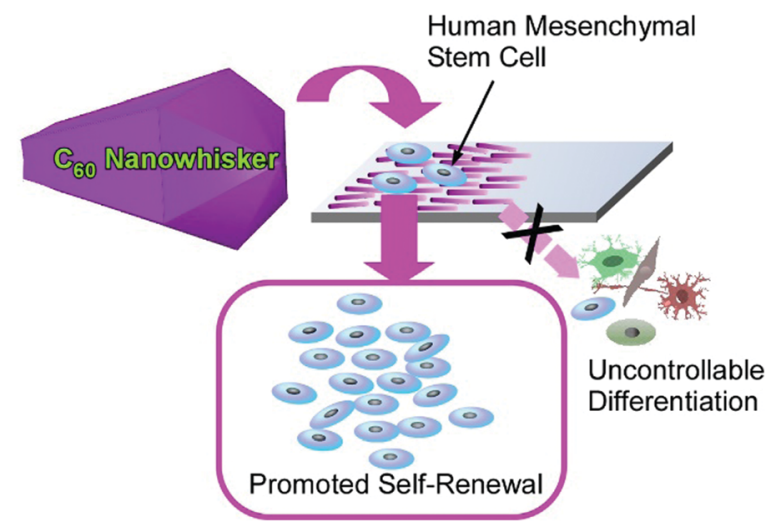

Fig. 22 Regulation of human mesenchymal stem cells for their enhanced renewal capability and multipotency on aligned one-dimensional fullerene nanowhiskers on a solid surface as large area scaffolds for cell culture. 
arrays of one-dimensional $\mathrm{C}_{60}$ nanowhiskers on a glass plate. The culture of human mesenchymal stem cells in the fabricated surface revealed their long-term multipotency retention and enhanced regenerative capacity, especially on a surface of aligned relatively longer $\mathrm{C}_{60}$ nanowhiskers. Appropriately modified contact between human mesenchymal stem cells and the fullerene-modified surface together with the regulated nucleus localization of Yes-associated protein could cause the ideal behaviour of human mesenchymal stem cells. Protein nanopatterns adsorbed on the fullerene nanowhisker arrays induced elongated focal adhesion parallelly along the long axes of onedimensional fullerene nanowhiskers, resulting in uniform unidirectional cell spreading. This situation could lead to the uniform activation of the mechano-transductive processes of human mesenchymal stem cells. Methylation and acetylation of histone patterns may be affected by the uniform elongation of the cells, which may stimulate the nuclei of the stem cells for their self-renewal patterns. Focal adhesions and F-actin polymerization promoted the localization of Yes-associated proteins from cytoplasm to the nucleus of human mesenchymal stem cells. This localization factor could promote the expression of stemness regulators. The obtained features of long-term self-renewal capability while preserving multipotency are favourable for therapies using human mesenchymal stem cells that often encounter the limited availability of stem cells without undesirable differentiation. In addition, this LB method with one-dimensional fullerene assemblies provides large area substrates for this ideal cell culture with easy processes. It would trigger nanoarchitectonics-based technologies for regenerative therapies using human mesenchymal stem cells. In this nanoarchitectonics strategy for stem cell control, various additional advantages such as high proliferation, cell shape control, biocompatibility, large-area culture, low cost, and simple procedures are satisfied. Therefore, significant contribution to stem cell technology can be expected in practical applications.

\section{Summary}

The design, synthesis, and production of functional materials are crucial keys to solve various current problems. These functional materials desirably have rational nanostructured motifs to accomplish the required demands with high efficiencies. The whole construction of such sophisticated materials through traditional synthetic techniques is usually tough. If we can architect complicated functional materials by only using simple molecular and nanoscopic units, the scientific and technological efforts to create functional materials would overcome the difficult synthetic barriers. An emerging concept, nanoarchitectonics, is supposed to produce functional materials using nanoscale units through various combined and/or selected processes. In order to exemplify the high potentials of this approach, the formation of materials with huge morphological varieties from simple unit components, fullerenes $\left(\mathrm{C}_{60}\right.$ and $\left.\mathrm{C}_{70}\right)$, is demonstrated in this review article. Fullerenes are actually zero-dimensional units made only from a single element component, carbon, but they can be converted

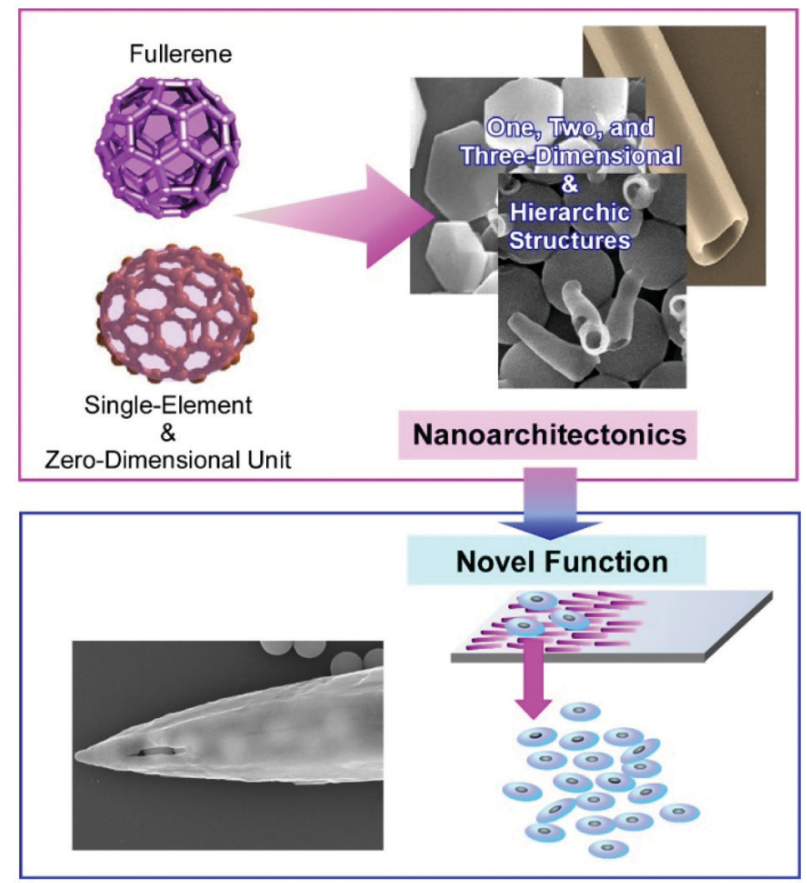

Fig. 23 Fullerenes as single-element and zero-dimensional units can be nanoarchitected into one-, two-, and three-dimensional structures and hierarchical architectures. The nanoarchitected fullerene structures express new functions such as microparticle capture and regulation of living cells.

into one-dimensional structures, two-dimensional morphologies, three-dimensional motifs, and even more complicated hierarchical architectures. Their applications are wide ranged from the molecular level to material sizes as demonstrated in their sensing applications, and the discrimination of macroscopic materials becomes possible on the basis of the specific micro-scaled structural features of well-architected fullerene assemblies materials. The higher-level functional feature can be even applied to regulate living cells (Fig. 23).

If sophisticated and systematic research efforts are made with the other construction units and their regulated combinations of units, this approach could create huge possibilities in material production for required applications. So far, a considerable number of approaches to create new functional materials have been taken on the basis of self-assembly and related processes rather separately. However, the unification and re-organization of this independent knowledge and facts with nanoarchitectonics would lead to a more logical understanding and pathway finding in ways of materials science. ${ }^{80}$

A crucial key to architect functional materials from nanounits would be the use of an interfacial environment. The selfassembly and self-organization of molecules and nanomaterials within defined two-dimensional media are more advantageous in well-expectable and well-designed assembled materials than those processes in expanded three-dimensional media. Anisotropy and orientation are easily created in the interfacial environment. As seen in many precipitation processes of fullerenes, the interfacial media can utilize the drastic changes in the natures of the 
contacting phases for material organization. Molecular recognition capability is often highly emphasized at the interfacial media, ${ }^{81}$ and macroscopic actions and nanoscopic events can be coupled at interfaces. ${ }^{82}$ For applications including biomedical $^{83}$ and physical usages, ${ }^{84}$ the connection of assembled materials with living cells and devices at interfaces becomes a crucial matter. Interfacial nanoarchitectonics would be one of the key concepts for future material choice. ${ }^{85}$ Recent advancement in analytical techniques enables us to observe molecular processes at nanocarbon interface. ${ }^{86}$ It is said that true innovation relies on the idea to create one from zero. This review article demonstrates this true innovation capability of nanoarchitectonics in material advances.

\section{Conflicts of interest}

There are no conflicts to declare.

\section{Acknowledgements}

This study was partially supported by JSPS KAKENHI Grant Number JP16H06518 (Coordination Asymmetry), JP20H00392, JP20H00316 and JP20K05590.

\section{Notes and references}

1 D. Guo, R. Shibuya, C. Akiba, S. Saji, T. Kondo and J. Nakamura, Science, 2016, 351, 36; N. Roy, N. Suzuki, C. Terashima and A. Fujishima, Bull. Chem. Soc. Jpn., 2019, 92, 178; T. Fujigaya, Bull. Chem. Soc. Jpn., 2019, 92, 400; A. E. Shalan, Mater. Adv., 2020, 1, 292.

2 M. Li, J. Lu, Z. Chen and K. Amine, Adv. Mater., 2018, 30, 1800561; H. Ohno, M. Yoshizawa-Fujita and Y. Kohno, Bull. Chem. Soc. Jpn., 2019, 92, 852; G. Liu, X. Wang, G. Han, J. Yu and H. Zhao, Mater. Adv., 2020, 1, 119; L. Miao, Z. Song, D. Zhu, L. Li, L. Gan and M. Liu, Mater. Adv., 2020, 1, 945; S. Dutta, J. Kim, Y. Ide, J. H. Kim, Md. S. A. Hossain, Y. Bando, Y. Yamauchi and K. C.-W. Wu, Mater. Horiz., 2017, 4, 522.

3 Y. Zhang, S. Yuan, G. Day, X. Wang, X. Yang, H.-C. Zhou, Y. Zhang, S. Yuan, G. Day, X. Wang, X. Yang and H.-C. Zhou, Coord. Chem. Rev., 2018, 354, 28; J. A. Jackman, A. R. Ferhan and N.-J. Cho, Bull. Chem. Soc. Jpn., 2019, 92, 1404; A. F. A. A. Melo, A. Hassan, L. J. A. Macedo, I. Osica, L. K. Shrestha, Q. Ji, O. N. Oliveira Jr., J. Henzie, K. Ariga and F. N. Crespilho, ACS Appl. Mater. Interfaces, 2019, 11, 18053; P. Pang, Y. Lai, Y. Zhang, H. Wang, X. A. Conlan, C. J. Barrow and W. Yang, Bull. Chem. Soc. Jpn., 2020, 93, 637.

4 S. Yu, X. Wang, H. Pang, R. Zhang, W. Song, D. Fu, T. Hayat and X. Wang, Chem. Eng. J., 2018, 333, 343; T. Sirinakorn, S. Bureekaew and M. Ogawa, Bull. Chem. Soc. Jpn., 2019, 92, 1; Y. Wu, H. Pang, Y. Liu, X. Wang, S. Yu, D. Fu, J. Chen and X. Wang, Environ. Pollut., 2019, 246, 608; Z. Li, Y. Sun, Y. Yang, Y. Han, T. Wang, J. Chen and D. C. W. Tsang, J. Hazard. Mater., 2020, 383, 121240.
5 B. L. Li, M. I. Setyawati, L. Chen, J. Xie, K. Ariga, C.-T. Lim, S. Garaj and D. T. Leong, ACS Appl. Mater. Interfaces, 2017, 9, 15286; J. Kumar and L. M. Liz-Marzán, Bull. Chem. Soc. Jpn., 2019, 92, 30; Y. Cai, Z. Wei, C. Song, C. Tang, W. Han and X. Dong, Chem. Soc. Rev., 2019, 48, 22; K. Fukunaga, H. Tsutsumi and H. Mihara, Bull. Chem. Soc. Jpn., 2019, 92, 391.

6 G. Povie, Y. Segawa, T. Nishihara, Y. Miyauchi and K. Itami, Science, 2017, 356, 172; Z. Sun, K. Ikemoto, T. M. Fukunaga, T. Koretsune, R. Arita, S. Sato and H. Isobe, Science, 2019, 363, 151; T. Niwa and T. Hosoya, Bull. Chem. Soc. Jpn., 2020, 93, 230; W. Muramatsu, T. Hattori and H. Yamamoto, Bull. Chem. Soc. Jpn., 2020, 93, 759.

7 K. Akagi, Bull. Chem. Soc. Jpn., 2019, 92, 1509; B. Grignard, S. Gennen, C. Jérôme, A. W. Kleij and C. Detrembleur, Chem. Soc. Rev., 2019, 48, 4466; S. Yamago, Bull. Chem. Soc. Jpn., 2020, 93, 287.

8 M. Ramanathan, L. K. Shrestha, T. Mori, Q. Ji, J. P. Hill and K. Ariga, Phys. Chem. Chem. Phys., 2013, 15, 10580; T. Takata, Bull. Chem. Soc. Jpn., 2019, 92, 409; S. Datta, Y. Kato, S. Higashiharaguchi, K. Aratsu, A. Isobe, T. Saito, D. D. Prabhu, Y. Kitamoto, M. J. Hollamby, A. J. Smith, R. Dalgliesh, N. Mahmoudi, L. Pesce, C. Perego, G. M. Pavan and S. Yagai, Nature, 2020, 583, 400.

9 C. B. Ong, L. Y. Ng and A. W. Mohammad, Renewable Sustainable Energy Rev., 2018, 81, 536; H. Kageyama, T. Yajima, Y. Tsujimoto, T. Yamamoto, C. Tassel and Y. Kobayashi, Bull. Chem. Soc. Jpn., 2019, 92, 1349; J. Shamsi, A. S. Urban, M. Imran, L. D. Trizio and L. Manna, Chem. Rev., 2019, 119, 3296; Y. Li, J. Henzie, T. Park, J. Wang, C. Young, H. Xie, J. W. Yi, J. Li, M. Kim, J. Kim, Y. Yamauchi and J. Na, Bull. Chem. Soc. Jpn., 2020, 93, 176; J. Wang, Y. Xu, B. Ding, Z. Chang, X. Zhang, Y. Yamauchi and K. C.-W. Wu, Angew. Chem., Int. Ed., 2018, 57, 2894; H. Konnerth, B. M. Matsagar, S. S. Chen, M. H. G. Prechtl, F.-K. Shieh and K. C.-W. Wu, Coord. Chem. Rev., 2020, 416, 213319.

10 T. Imaoka and K. Yamamoto, Bull. Chem. Soc. Jpn., 2019, 92, 941; W.-H. Soe, C. Manzano, R. Robles, N. Lorente and C. Joachim, Nano Lett., 2020, 20, 384; T. Shimizu, D. Lungerich, J. Stuckner, M. Murayama, K. Harano and E. Nakamura, Bull. Chem. Soc. Jpn., 2020, 93, 1079; S. Kawai, O. Krejčí, T. Nishiuchi, K. Sahara, T. Kodama, R. Pawlak, E. Meyer, T. Kubo and A. S. Foster, Sci. Adv., 2020, 6, eaay8913.

11 K. Ariga, Q. Ji, W. Nakanishi, J. P. Hill and M. Aono, Mater. Horiz., 2015, 2, 406; K. Ariga and Y. Yamauchi, Chem. - Asian J., 2020, 15, 718.

12 M. Roukes, Sci. Am., 2001, 285, 48; K. Ariga, J. Inorg. Organomet. Polym., 2015, 25, 177.

13 K. Ariga, Q. Ji, J. P. Hill, Y. Bando and M. Aono, NPG Asia Mater., 2012, 4, e17; K. Ariga, Trends Chem., 2020, 2, 779.

14 K. Ariga, M. Li, G. J. Richards and J. P. Hill, J. Nanosci. Nanotechnol., 2011, 11, 1; K. Ariga, J. Li, J. Fei, Q. Ji and J. P. Hill, Adv. Mater., 2016, 28, 1251.

15 M. Aono and K. Ariga, Adv. Mater., 2016, 28, 989; K. Ariga, Mater. Chem. Front., 2017, 1, 208. 
16 K. Ariga, X. Jia, J. Song, J. P. Hill, D. T. Leong, Y. Jia and J. Li, Angew. Chem., Int. Ed., 2020, 59, 15269.

17 S. Ishihara, J. Labuta, W. Van Rossom, D. Ishikawa, K. Minami, J. P. Hill and K. Ariga, Phys. Chem. Chem. Phys., 2014, 16, 9713; M. Komiyama, T. Mori and K. Ariga, Bull. Chem. Soc. Jpn., 2018, 91, 1075; J. Liu, H. Zhou, W. Yang and K. Ariga, Acc. Chem. Res., 2020, 53, 644.

18 H. Abe, J. Liu and K. Ariga, Mater. Today, 2016, 19, 12; D. Kim, M. Gu, M. Park, T. Kim and B.-S. Kim, Mol. Syst. Des. Eng., 2019, 4, 65; F. Wu, K. Eid, A. M. Abdullah, W. Niu, C. Wang, Y. Lan, A. A. Elzatahry and G. Xu, ACS Appl. Mater. Interfaces, 2020, 12, 31309.

19 K. Ariga, S. Watanabe, T. Mori and J. Takeya, NPG Asia Mater., 2018, 10, 90; J. M. Giussi, M. L. Cortez, W. A. Marmisollé and O. Azzaroni, Chem. Soc. Rev., 2019, 48, 814; K. Ariga, M. Ito, T. Mori, S. Watanabe and J. Takeya, Nano Today, 2019, 28, 100762.

20 J. Kim, J. H. Kim and K. Ariga, Joule, 2017, 1, 739; Y. Guo, T. Park, J. W. Yi, J. Henzie, J. Kim, Z. Wang, B. Jiang, Y. Bando, Y. Sugahara, J. Tang and Y. Yamauchi, Adv. Mater., 2019, 31, 1807134.

21 K. Ariga, S. Ishihara, H. Abe, M. Li and J. P. Hill, J. Mater. Chem., 2012, 22, 2369; P. Cheng, C. Wang, Y. V. Kaneti, M. Eguchi, J. Lin, Y. Yamauchi and J. Na, Langmuir, 2020, 36, 4231.

22 W. Nakanishi, K. Minami, L. K. Shrestha, Q. Ji, J. P. Hill and K. Ariga, Nano Today, 2014, 9, 378; L. Zhao, Q. Zou and X. Yan, Bull. Chem. Soc. Jpn., 2019, 92, 70; K. Ariga, D. T. Leong and T. Mori, Adv. Funct. Mater., 2018, 28, 1702905.

23 K. Ariga, A. Vinu, Y. Yamauchi, Q. Ji and J. P. Hill, Bull. Chem. Soc. Jpn., 2012, 85, 1; A. V. N. Kumar, S. Yin, Z. Wang, X. Qian, D. Yang, Y. Xu, X. Li, H. Wang and L. Wang, New J. Chem., 2019, 43, 9628.

24 G. Rydzek, Q. Ji, M. Li, P. Schaaf, J. P. Hill, F. Boulmedais and K. Ariga, Nano Today, 2015, 10, 138; K. Ariga, T. Mori, T. Kitao and T. Uemura, Adv. Mater., 2020, 32, 1905657.

25 K. Ariga, Q. Ji, T. Mori, M. Naito, Y. Yamauchi, H. Abe and J. P. Hill, Chem. Soc. Rev., 2013, 42, 6322; B. Roy and T. Govindaraju, Bull. Chem. Soc. Jpn., 2019, 92, 1883; X. Liang, L. Li, J. Tang, M. Komiyama and K. Ariga, Bull. Chem. Soc. Jpn., 2020, 93, 581.

26 L. K. Shrestha, Q. Ji, T. Mori, K. Miyazawa, Y. Yamauchi, J. P. Hill and K. Ariga, Chem. - Asian J., 2013, 8, 1662; K. Ariga and L. K. Shrestha, Materials, 2020, 13, 2280.

27 Y. Xu, R. Kaur, B. Wang, M. B. Minameyer, S. Gsänger, B. Meyer, T. Drewello, D. M. Guldi and M. von Delius, J. Am. Chem. Soc., 2018, 140, 13413; S. Toyota, Y. Yamamoto, K. Wakamatsu, E. Tsurumaki and A. Muñoz-Castro, Bull. Chem. Soc. Jpn., 2019, 92, 1721.

28 T. Umeyama and H. Imahori, Acc. Chem. Res., 2019, 52, 2046; T. Akiyama, Bull. Chem. Soc. Jpn., 2019, 92, 1181.

29 M. Li, Z.-K. Wang, T. Kang, Y. Yang, X. Gao, C.-S. Hsu, Y. Li and L.-S. Liao, Nano Energy, 2018, 43, 47; Q. Hou, J. Ren, H. Chen, P. Yang, Q. Shao, M. Zhao, X. Zhao, H. He, N. Wang, Q. Luo and Z. Guo, ChemElectroChem, 2018,
5, 726; S. Collavini and J. L. Delgado, Sustainable Energy Fuels, 2018, 2, 2480; J. Pascual, J. L. Delgado and R. TenaZaera, J. Phys. Chem. Lett., 2018, 9, 2893.

30 T. Nakanishi, N. Miyashita, T. Michinobu, Y. Wakayama, T. Tsuruoka, K. Ariga and D. G. Kurth, J. Am. Chem. Soc., 2006, 128, 6328; T. Michinobu, T. Nakanishi, J. P. Hill, M. Funahashi and K. Ariga, J. Am. Chem. Soc., 2006, 128, 10384; T. Nakanishi, T. Michinobu, K. Yoshida, N. Shirahata, K. Ariga, H. Möhwald and D. Kurth, Adv. Mater., 2008, 20, 443. 31 K. Miyazawa, J. Nanosci. Nanotechnol., 2009, 9, 41; K. Miyazawa, Sci. Technol. Adv. Mater., 2015, 16, 013502.

32 L. K. Shrestha, R. G. Shrestha, Y. Yamauchi, J. P. Hill, T. Nishimura, K. Miyazawa, T. Kawai, S. Okada, K. Wakabayashi and K. Ariga, Angew. Chem., Int. Ed., 2015, 54, 951.

33 P. Bairi, R. G. Shrestha, J. P. Hill, T. Nishimura, K. Ariga and L. K. Shrestha, J. Mater. Chem. A, 2016, 4, 13899.

34 G. S. Kumar, R. G. Shrestha, Q. Ji, J. P. Hill, K. Ariga, S. Acharya and L. K. Shrestha, Phys. Chem. Chem. Phys., 2018, 20, 18873.

35 N. Furuuchi, R. G. Shrestha, Y. Yamashita, T. Hirao, K. Ariga and L. K. Shrestha, Sensors, 2019, 19, 267.

36 J.-B. Wu, M.-L. Lin, X. Cong, H.-N. Liu and P.-H. Tan, Chem. Soc. Rev., 2018, 47, 1822; C. N. R. Rao and K. Pramoda, Bull. Chem. Soc. Jpn., 2019, 92, 441; C. Sengottaiyan, R. Jayavel, R. G. Shrestha, T. Subramani, S. Maji, J. H. Kim, J. P. Hill, K. Ariga and L. K. Shrestha, Bull. Chem. Soc. Jpn., 2019, 92, 521; B. Wang, T. Ruan, Y. Chen, F. Jin, L. Peng, Y. Zhou, D. Wang and S. Dou, Energy Storage Mater., 2020, 24, 22.

37 Q. Yun, Q. Lu, X. Zhang, C. Tan and H. Zhang, Angew. Chem., Int. Ed., 2018, 57, 626; C. Min Lee, C. H. Jin, C. H. Ahn, H. K. Cho, J. H. Lim, S. M. Hwang and J. Joo, Bull. Chem. Soc. Jpn., 2019, 92, 1094; B. Chen, D. Chao, E. Liu, M. Jaroniec, N. Zhao and S.-Z. Qiao, Energy Environ. Sci., 2020, 13, 1096.

38 T. Su, Q. Shao, Z. Qin, Z. Guo and Z. Wu, ACS Catal., 2018, 8, 2253; K. Maeda and T. E. Mallouk, Bull. Chem. Soc. Jpn., 2019, 92, 38; Y. Yamamoto, H. Imai and Y. Oaki, Bull. Chem. Soc. Jpn., 2019, 92, 779; H. Taniguchi, K. Akiyama and T. Fujie, Bull. Chem. Soc. Jpn., 2020, 93, 1007.

39 Y. Oishi, Y. Torii, T. Kato, M. Kuramori, K. Suehiro, K. Ariga, K. Taguchi, A. Kamino, H. Koyano and T. Kunitake, Langmuir, 1997, 13, 519; J. P. Hill, Y. Wakayama and K. Ariga, Phys. Chem. Chem. Phys., 2006, 8, 5034; S. Ito, T. Nakamura and M. Nakagawa, Bull. Chem. Soc. Jpn., 2020, 93, 862.

40 R. Makiura, S. Motoyama, Y. Umemura, H. Yamanaka, O. Sakata and H. Kitagawa, Nat. Mater., 2010, 9, 565; A. Azhar, M. B. Zakaria, J. Kim, J. Na, Y. V. Kaneti, A. Fatehmulla, A. M. Aldhafiri, W. A. Farooq, Y. Bando, Y. Yamauchi and J. Lin, Bull. Chem. Soc. Jpn., 2019, 92, 1263; D. Zhu, M. Qiao, J. Liu, T. Tao and C. Guo, J. Mater. Chem. A, 2020, 8, 8143.

41 Y. Jin, Y. Hu and W. Zhang, Nat. Rev. Chem., 2017, 1, 0056; D. Rodríguez-San-Miguel, C. Montoro and F. Zamora, Chem. Soc. Rev., 2020, 49, 2291.

42 T. Mori, H. Tanaka, A. Dalui, N. Mitoma, K. Suzuki, M. Matsumoto, N. Aggarwal, A. Patnaik, S. Acharya, 
L. K. Shrestha, H. Sakamoto, K. Itami and K. Ariga, Angew. Chem., Int. Ed., 2018, 57, 9679.

43 X. Jia, K. Minami, K. Uto, A. C. Chang, J. P. Hill, T. Ueki, J. Nakanishi and K. Ariga, Small, 2019, 15, 1804640; K. Ariga, X. Jia, J. Song, C.-T. Hsieh and S.-H. Hsu, ChemNanoMat, 2019, 5, 692; X. Jia, K. Minami, K. Uto, A. C. Chang, J. P. Hill, J. Nakanishi and K. Ariga, Adv. Mater., 2020, 32, 1905942; J. Song, X. Jia and K. Ariga, Small Methods, 2020, 4, 2000500.

44 K. Ariga, M. Matsumoto, T. Mori and L. K. Shrestha, Beilstein J. Nanotechnol., 2019, 10, 1559.

45 M. Sathish and K. Miyazawa, J. Am. Chem. Soc., 2007, 129, 13816.

46 M. Sathish, K. Miyazawa, J. P. Hill and K. Ariga, J. Am. Chem. Soc., 2009, 131, 6372.

47 L. K. Shrestha, Y. Yamauchi, J. P. Hill, K. Miyazawa and K. Ariga, J. Am. Chem. Soc., 2013, 135, 586.

48 Q. Tang, P. Bairi, R. G. Shrestha, J. P. Hill, K. Ariga, H. Zeng, Q. Ji and L. K. Shrestha, ACS Appl. Mater. Interfaces, 2017, 9, 44458.

49 J. Kim, C. Park, I. Song, M. Lee, H. Kim and H. C. Choi, Sci. Rep., 2016, 6, 32205.

50 S. Kang, J. Zhang, L. Sang, L. K. Shrestha, Z. Zhang, P. Lu, F. Li, M. Li and K. Ariga, ACS Appl. Mater. Interfaces, 2016, 8, 24295.

51 C. Park, E. Yoon, M. Kawano, T. Joo and H. C. Choi, Angew. Chem., Int. Ed., 2010, 49, 9670.

52 L. K. Shrestha, M. Sathish, J. P. Hill, K. Miyazawa, T. Tsuruoka, N. M. Sanchez-Ballester, I. Honma, Q. Ji and K. Ariga, J. Mater. Chem. C, 2013, 1, 1174.

53 P. Bairi, T. Tsuruoka, S. Acharya, Q. Ji, J. P. Hill, K. Ariga, Y. Yamauchi and L. K. Shrestha, Mater. Horiz., 2018, 5, 285.

54 P. Bairi, S. Maji, J. P. Hill, J. H. Kim, K. Ariga and L. K. Shrestha, J. Mater. Chem. A, 2019, 7, 12654.

55 J. Kim, C. Park and H. C. Choi, Chem. Mater., 2015, 27, 2408.

56 L. K. Shrestha, R. G. Shrestha, J. P. Hill, T. Tsuruoka, Q. Ji, T. Nishimura and K. Ariga, Langmuir, 2016, 32, 12511.

57 S. Zheng, N. T. Cuong, S. Okada, T. Xu, W. Shen, X. Lu and K. Tsukagoshi, Chem. Mater., 2018, 30, 7146.

58 B. Wang, Y. Qu, G. Piao and D. M. Guldi, ACS Appl. Mater. Interfaces, 2019, 11, 16567.

59 I. K. Alsulami, T. M. D. Alharbi, D. P. Harvey, C. T. Gibson and C. L. Raston, Chem. Commun., 2018, 54, 7896.

60 T. Nakanishi, W. Schmitt, T. Michinobu, D. G. Kurth and K. Ariga, Chem. Commun., 2005, 5982.

61 P. Bairi, K. Minami, W. Nakanishi, J. P. Hill, K. Ariga and L. K. Shrestha, ACS Nano, 2016, 10, 6631.

62 Y. Lei, S. Wang, Z. Lai, X. Yao, Y. Zhao, H. Zhang and H. Chen, Nanoscale, 2019, 11, 8692.

63 S. Yamamoto, Y. Funamori, Y. Kaneda, M. Tanimura and M. Tachibana, Chem. Phys. Lett., 2019, 730, 105.

64 P. Bairi, K. Minami, J. P. Hill, W. Nakanishi, L. K. Shrestha, C. Liu, K. Harano, E. Nakamura and K. Ariga, ACS Nano, 2016, 10, 8796.

65 F. Han, R. Wang, Y. Feng, S. Wang, L. Liu, X. Li, Y. Han and H. Chen, Nat. Commun., 2019, 10, 1548.

66 F. Han, R. Wang, B. Chen, Y. Feng, H. Liu, S. Wang, D. Su, H. Zhang and H. Chen, J. Am. Chem. Soc., 2020, 142, 15396.
67 M. R. Benzigar, S. N. Talapaneni, S. Joseph, K. Ramadass, G. Singh, J. Scaranto, U. Ravon, K. Al-Bahilyc and A. Vinu, Chem. Soc. Rev., 2018, 47, 2680; A. Glotov, A. Stavitskaya, Y. Chudakov, E. Ivanov, W. Huang, V. Vinokurov, A. Zolotukhina, A. Maximov, E. Karakhanov and Y. Lvov, Bull. Chem. Soc. Jpn., 2019, 92, 61; G. Sai-Anand, A. Sivanesan, M. R. Benzigar, G. Singh, A.-I. Gopalan, A. V. Baskar, H. Ilbeygi, K. Ramadass, V. Kambala and A. Vinu, Bull. Chem. Soc. Jpn., 2019, 92, 216; M. Gao, J. Zeng, K. Liang, D. Zhao and B. Kong, Adv. Funct. Mater., 2020, 30, 1906950; R. Ryoo, J. Kim, C. Jo, S. W. Han, J.-C. Kim, H. Park, J. Han, H. S. Shin and J. W. Shin, Nature, 2020, 585, 221.

68 L. Jiao, Y. Wang, H.-L. Jiang and Q. Xu, Adv. Mater., 2018, 30, 1703663; T. Sanada, S. Tominaka, K. Kojima and A. K. Cheetham, Bull. Chem. Soc.Jpn., 2019, 92, 427; Q. Wang and D. Astruc, Chem. Rev., 2020, 120, 1438.

69 C. Gu, N. Hosono, J.-J. Zheng, Y. Sato, S. Kusaka, S. Sakaki and S. Kitagawa, Science, 2019, 363, 387; A. Azhar, Y. Li, Z. Cai, M. B. Zakaria, M. K. Masud, Md. S. A. Hossain, J. Kim, W. Zhang, J. Na, Y. Yamauchi and M. Hu, Bull. Chem. Soc. Jpn., 2019, 92, 875; C. V. Nguyen, W.-H. Chiang and K. C.-W. Wu, Bull. Chem. Soc. Jpn., 2019, 92, 1430; J.-Q. Liu, Z.-D. Luo, Y. Pan, A. K. Singh, M. Trivedi and A. Kumar, Coord. Chem. Rev., 2020, 406, 213145.

70 M. R. Benzigar, S. Joseph, A. V. Baskar, D.-H. Park, G. Chandra, S. Umapathy, S. N. Talapaneni and A. Vinu, Adv. Funct. Mater., 2018, 28, 1803701.

71 C.-T. Hsieh, S.-h. Hsu, S. Maji, M. K. Chahal, J. Song, J. P. Hill, K. Ariga and L. K. Shrestha, Mater. Horiz., 2020, 7, 787.

72 T. Kakuta, T. Yamagishi and T. Ogoshi, Acc. Chem. Res., 2018, 51(7), 1656; H. Muraoka, H. Sasaki and S. Ogawa, Bull. Chem. Soc. Jpn., 2019, 92, 797; K. Murakami and K. Waizumi, Bull. Chem. Soc. Jpn., 2020, 93, 1095; Y.-M. Zhang, Y.-H. Liu and Y. Liu, Adv. Mater., 2020, 32, 1806158.

73 P. Bairi, K. Minami, J. P. Hill, K. Ariga and L. K. Shrestha, ACS Nano, 2017, 11, 7790.

74 J. Wu, X. Zhu, Y. Guan, Y. Wang, F. Jin, R. Guan, F. Liu, M. Chen, Y. Tian and S. Yang, Angew. Chem., Int. Ed., 2019, 58, 11350.

75 Q. Tang, S. Maji, B. Jiang, J. Sun, W. Zhao, J. P. Hill, K. Ariga, H. Fuchs, Q. Ji and L. K. Shrestha, ACS Nano, 2019, 13, 14005 .

76 J. H.-C. Wang, J. Biomech., 2006, 39, 1563; K. Ariga, K. Minami, M. Ebara and J. Nakanishi, Polym. J., 2016, 48, 371; B. Ladoux and R.-M. Mège, Nat. Rev. Molec. Cell Biol., 2017, 18, 743.

77 K. Minami, Y. Kasuya, T. Yamazaki, Q. Ji, W. Nakanishi, J. P. Hill, H. Sakai and K. Ariga, Adv. Mater., 2015, 27, 4020.

78 V. Krishnan, Y. Kasuya, Q. Ji, M. Sathish, L. K. Shrestha, S. Ishihara, K. Minami, H. Morita, T. Yamazaki, N. Hanagata, K. Miyazawa, S. Acharya, W. Nakanishi, J. P. Hill and K. Ariga, ACS Appl. Mater. Interfaces, 2015, 7, 15667.

79 J. Song, X. Jia, K. Minami, J. P. Hill, J. Nakanishi and L. K. Shrestha, ACS Appl. Nano Mater., 2020, 3, 6497. 
80 K. Ariga, M. Nishikawa, T. Mori, J. Takeya, L. K. Shrestha and J. P. Hill, Sci. Technol. Adv. Mater., 2019, 20, 51; K. Ariga, E. Ahn, M. Park and B.-S. Kim, Chem. Asian J., 2019, 14, 2553; K. Ariga and L. K. Shrestha, APL Mater., 2019, 7, 120903.

81 K. Ariga and T. Kunitake, Acc. Chem. Res., 1998, 31, 371; K. Ariga, H. Ito, J. P. Hill and H. Tsukube, Chem. Soc. Rev., 2012, 41, 5800; K. Ariga, T. Mori and J. Li, Langmuir, 2019, 35, 3585; K. Ariga, Phys. Chem. Chem. Phys., 2020, 22, 24856.

82 K. Ariga, T. Mori and J. P. Hill, Adv. Mater., 2012, 24, 158; K. Ariga, Y. Yamauchi, T. Mori and J. P. Hill, Adv. Mater., 2013, 25, 6477; K. Ariga, M. Ishii and T. Mori, Chem. - Eur. J., 2020, 26, 6461; K. Ariga, ChemNanoMat, 2020, 6, 870; K. Ariga, Chem. Sci., 2020, 11, 10594.

83 J. Kobayashi and T. Okano, Bull. Chem. Soc. Jpn., 2019, 92, 817; M. Tanaka, S. Kobayashi, D. Murakami, F. Aratsu,
A. Kashiwazaki, T. Hoshiba and K. Fukushima, Bull. Chem. Soc. Jpn., 2019, 92, 2043.

84 Y. Watanabe, H. Sasabe and J. Kido, Bull. Chem. Soc. Jpn., 2019, 92, 716; D. Okaue, I. Tanabe, S. Ono, K. Sakamoto, T. Sato, A. Imanishi, Y. Morikawa, J. Takeya and K. Fukui, J. Phys. Chem. C, 2020, 124, 2543.

85 K. Ariga, M. V. Lee, T. Mori, X.-Y. Yu and J. P. Hill, Adv. Colloid Interface Sci., 2010, 154, 20; K. Takada, Langmuir, 2013, 29, 7538; K. Ariga, T. Mori and J. P. Hill, Langmuir, 2013, 29, 8459; K. Ariga, M. Ishii and T. Mori, Curr. Opin. Colloid Interface Sci., 2019, 44, 1; K. Ariga, Langmuir, 2020, 36, 7158.

86 K. Kamei, T. Shimizu, K. Harano and E. Nakamura, Bull. Chem. Soc. Jpn., 2020, 93, 1603; Y. Kratish, T. Nakamuro, Y. Liu, J. Li, I. Tomotsuka, K. Harano, E. Nakamura and T. J. Marks, Bull. Chem. Soc, DOI: 10.1246/bcsj.20200299. 